\title{
Kinetic Studies of Hydroxyquinone Formation from Water Soluble Benzoquinones
}

Éva Józsa, ${ }^{a}$ Mihály Purgel, ${ }^{\mathrm{a}, \mathrm{b}}$ Marianna Bihari, ${ }^{\mathrm{a}}$ Péter Pál Fehér, ${ }^{\mathrm{a}}$ Gábor Sustyák, ${ }^{\mathrm{a}}$ Balázs Várnagy, ${ }^{\mathrm{a}}$ Virág Kiss, ${ }^{\mathrm{a}}$ Eszter Ladó, ${ }^{\mathrm{a}}$ Katalin Ösz ${ }^{\mathrm{a}}$

${ }^{a}$ Department of Physical Chemistry, University of Debrecen, H-4032 Debrecen, Egyetem tér 1., Hungary

${ }^{\mathrm{b}}$ Research Group of Homogeneous Catalysis and Reaction Mechanism, H-4032 Debrecen, Egyetem tér 1., Hungary

*Corresponding author. Tel: + 36 52-512-900 Ext.: 22387; E-mail:

osz.katalin@science.unideb.hu 


\section{Table of contents entry}

The kinetics of the reactions between 1,4-benzoquinones and hydrogen peroxide were studied. A systematic study of substituent effects revealed a Hammett-like correlation, where the rate of reaction is mainly determined by electronic effects.

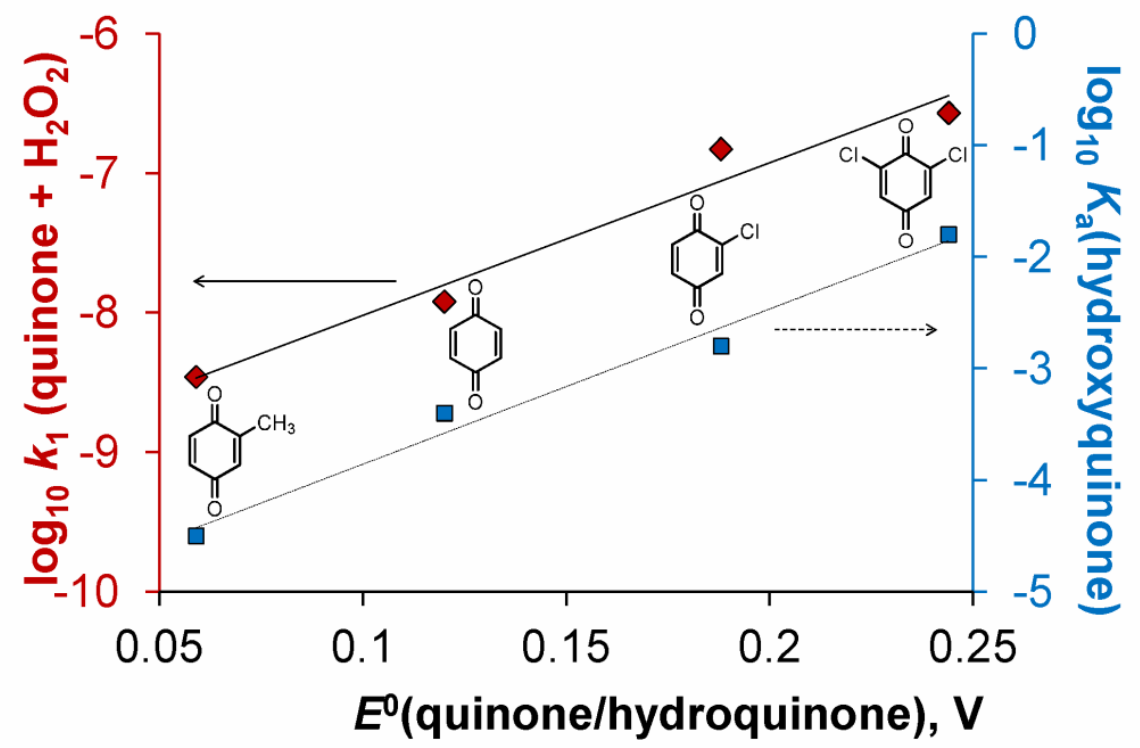




\begin{abstract}
The kinetics and mechanisms of the redox reactions between hydrogen peroxide and 1,4benzoquinone, 2-methyl-1,4-benzoquinone, 2,6-dimethyl-1,4-benzoquinone, 2-chloro-1,4benzoquinone and 2,6-dichloro-1,4-benzoquinone were studied in aqueous media using spectrophotometric monitoring. The formation and decay of a hydroxylated 1,4-benzoquinone was detected. The formation of the intermediate was first order with respect to the parent 1,4bezoquinone and hydrogen peroxide, whereas inverse first order dependence was revealed with respect to hydrogen ion. The decomposition reaction had two parallel pathways: one was first order with respect to the intermediate, while the other showed second-order dependence. The values of the rate constant measured for the formation step were successfully correlated with both the redox potentials of the substituted quinone/hydroquinone systems and the $\mathrm{p} K_{\mathrm{a}}$ values of the hydroxylated quinone derivatives. Therefore, electronic effects govern the reactivity of the quinones in this process. NMR and GC-MS measurements were carried out to identify the products in the system. Quantum mechanical calculations were also carried out in these systems.
\end{abstract}




\section{Introduction}

Benzoquinones play an important role in the living organisms as electron acceptors. ${ }^{1,2}$ Bioelectrochemical cells were constructed to utilize solar energy, mimicking the photosynthetic system using a quinone as a mediator. ${ }^{3,4}$ Upon the UV irradiation of benzoquinone derivatives in aqueous media, hydroquinone, hydroxyquinone and oxygen are formed. ${ }^{5-7}$ In photoelectrochemical energy conversion systems, hydroxylation of quinones is considered a side reaction because it decreases the amount of the reducible compound thus causing the decay of such cells. The effect of substituents on the hydroxyquinone formation and the quinone reduction is not well understood. ${ }^{7}$ The direct formation of hydroxyquinone in the photochemical process is unlikely because the triplet excited states of benzoquinones are strong oxidizing agents. ${ }^{8,9}$ Thus, it is more likely that this triplet quinone oxidizes another quinone molecule to hydroxyquinone.

Triplet quinone is highly unstable in aqueous solution. To understand the reaction mechanism to hydroxyquinone oxidation and the substituent effects in this reaction, more stable oxidizing agents are required that do not react with water. Our choices were hydrogen peroxide and periodate ion.

The oxidation of numerous quinones to hydroxyquinones was reported in the literature. ${ }^{10}$ Hydroxy-para-benzoquinone, 2-hydroxy-5-methoxy-3-(8',Z, 11' Z)-pentadeca-8', 11',14',-trienyl-1,4-benzoquinone, metachromin-A, 2-hydroxyphenanthrene-1,4-quinone were prepared through the Thiele-Winter acetoxylation. ${ }^{11-17}$ Hydroxy-benzoquinone was prepared by the oxidation of hydroxyhydroquinone (benzene-1,2,4-triol). ${ }^{18,19}$ 6-Hydroxy-1,2,3,4tetrahydronaphthalene-5,8-dione was obtained by the demethylation of the trimethoxy derivatives. ${ }^{20}$ The synthesis of naturally occurring maesanin, (-)-illimaquinone, $( \pm)-$ mamanuthaquinone was carried out by the oxidative demethylation of tetramethoxybenzene with cerium(IV) ammonium nitrate. ${ }^{21-23}$ 
The kinetics of the formation of 3,5-dichloro-2-hydroxy-1,4-benzoquinone was studied in detail in the oxidation reaction of 2,6-dichloro-1,4-benzoquinone with hydrogen peroxide as a function of reactant concentrations and $\mathrm{pH}$. The process was found to be first order with respect to both reagents and inverse first order with respect to hydrogen ion concentration. This latter finding was explained by the assumption that the deprotonated form of hydrogen peroxide, $\mathrm{HO}_{2}{ }^{-}$, is the actual reactive form of the oxidizing agent even though the $\mathrm{pH}$ range of the studies was far from the known first $\mathrm{p} K_{\mathrm{a}}$ of $\mathrm{H}_{2} \mathrm{O}_{2}$. This interpretation was in good qualitative agreement with the fact that extremely fast reaction rates were found at higher $\mathrm{pH}$, but evidence for the occurrence of numerous side reactions were also obtained in this more basic medium. ${ }^{24}$

In this paper, our aim was to study the formation kinetics of some hydroxyquinones containing electron donating or electron withdrawing substituents. The hydroxyquinone derivatives were formed by oxidizing the corresponding 1,4-benzoquinones with hydrogen peroxide or potassium periodate in aqueous solution. Hydrogen peroxide is a strong oxidizing agent that has high oxidation potential in a wide $\mathrm{pH}$ range: $E=1.763 \mathrm{~V}$ at $\mathrm{pH} 0$ and $E=0.878$ $\mathrm{V}$ at $\mathrm{pH} 14 .{ }^{25}$ It is used extensively in chemical syntheses since its decomposition products, namely $\mathrm{H}_{2} \mathrm{O}$ and $\mathrm{O}_{2}$ are environmentally friendly, but its reactivity is often moderate: catalysts are regularly needed in its reactions. In addition, stock solutions of hydrogen peroxide are not very stable and cannot be stored for extended times. Potassium periodate was the other oxidant used here. Due to its high oxidizing power and high reactivity, it is often used in organic oxidation reactions. In its solid form, no stability problems are encountered and the oxidation by-product, iodide ion, does not pose a major known environmental risk. There seems to be a literature contradiction about the dominating aqueous form of periodate ion $\left(\mathrm{IO}_{4}{ }^{-}\right.$or $\left.\mathrm{H}_{4} \mathrm{IO}_{6}{ }^{-}\right),{ }^{26-30}$ but this is seldom important from the view point of redox chemistry. 


\section{Experimental}

\subsection{Materials}

Solid 1,4-benzoquinone (Q) and its derivatives $(\mathrm{QR})$ were purchased from Alfa Aesar and used as received. The concentrations of the stock solutions in our experiments were typically $1 \times 10^{-3} \mathrm{~mol} \mathrm{dm} \mathrm{dm}^{-3}$ 1,4-Benzoquinones are photosensitive compounds in solution, ${ }^{7,8,31-37}$ therefore fresh solutions were prepared for all experiments in brown glass volumetric flask.

$30 \%(\mathrm{w} / \mathrm{w})$ hydrogen peroxide solution (analytical grade, purissimum) was purchased from VWR. The accurate concentrations of the solutions used for the oxidation experiments were determined by permanganometric titrations.

Solid potassium periodate was purchased from Reanal, Hungary and used without further purification to prepare aqueous stock solutions.

Oxidation reactions were proved to be $\mathrm{pH}$ sensitive. Therefore, $\mathrm{NaH}_{2} \mathrm{PO}_{4} / \mathrm{Na}_{2} \mathrm{HPO}_{4}$ buffer solutions at $\mathrm{pH} \sim 6.5$ were prepared using sodium dihydrogen phosphate dihydrate (analytical grade, normapur) and di-sodium hydrogen phosphate dodecahydrate (analytical grade, normapur), both purchased from VWR. For further experiments at $\mathrm{pH} \sim 4.5$, $\mathrm{CH}_{3} \mathrm{COOH} / \mathrm{CH}_{3} \mathrm{COONa}$ buffer solutions were prepared using the two buffer components purchased from VWR.

\subsection{Instruments and softwares for kinetic measurements}

$\mathrm{pH}$ measurements of the buffered benzoquinone solutions were carried out using a Methrohm hydrogen ion selective glass electrode binding with an ABU 93 Triburette potentiometric titrator. The stability of the $\mathrm{pH}$ was also followed during some of the kinetic runs for a total of 8-hour measurement time.

A Shimadzu UV-1601 double beam spectrophotometer with UV-Probe software was used for the kinetic study on the formation and the decomposition of hydroxyquinones. After 
measuring the spectrum of the hydroxyquinone product, only one wavelength at the maximum absorbance in the visible range was used to follow the reaction. In contrast with a diode array spectrophotometer and full-scan mode, the light intensity passing through the samples in this way is low enough not to initiate photochemical decomposition of 1,4-benzoquinones. This was also proved experimentally. Most reactions (except for the temperature dependent kinetic curves) were measured in $1.00-\mathrm{cm}$ path length quartz cuvettes at $25.0 \pm 0.1{ }^{\circ} \mathrm{C}$.

Temperature dependent kinetic measurements were performed after a 10-min prethermostation period of the samples and in the $10-40{ }^{\circ} \mathrm{C}$ temperature range.

For the oxidation reactions of unsubstituted 1,4-benzoquinone and at higher hydrogen peroxide concentrations, rapid kinetic experiments were carried out in an Applied Photophysics DX-17 MV stopped-flow instrument with a photomultiplier tube as the detector. Absorbance traces were collected using an optical cell of $1.00 \mathrm{~cm}$ path length. The dead time of the stopped-flow instrument was determined to be $1.51 \pm 0.03 \mathrm{~ms}$ using a standard method. ${ }^{38}$

The least squares fitting of the measured data was carried out using the general fitting software MicroMath SCIENTIST. ${ }^{39}$

\subsection{GC-MS measurements}

For the GC-MS measurements, a sample containing the benzoquinone derivative in $1 \times 10^{-3}$ mol dm${ }^{-3}$ and $\mathrm{H}_{2} \mathrm{O}_{2}$ in $0.576 \mathrm{~mol} \mathrm{dm}^{-3}$ concentration was prepared. The reaction was followed spectrophotometrically. One GC-MS measurement was performed when the concentration of the hydroxyquinone was at the maximum, and another after 1 day, when the decomposition of the hydroxyquinone was complete. A GC-MS measurement of a sample containing only the benzoquinone was also performed.

The measurements were carried out using a Shimadzu GCMS-QP2010plus system. Compounds were separated on a Zebron ZB-5MS capillary column $(30 \mathrm{~m} \times 0.25 \mathrm{~mm}$ i.d. $\times$ 
$0.25 \mu \mathrm{m}$.). The temperature of the column was $50{ }^{\circ} \mathrm{C}$ for $1.5 \mathrm{~min}$ after injection. Later, it was programmed to increase at $20{ }^{\circ} \mathrm{C} \min ^{-1}$ to $100{ }^{\circ} \mathrm{C}$ then at $10{ }^{\circ} \mathrm{C} \min ^{-1}$ to $280{ }^{\circ} \mathrm{C}$, and finally maintained at that temperature for $4 \mathrm{~min}$. Helium was used as the carrier gas and the injector temperature was $300{ }^{\circ} \mathrm{C}$. A split ratio of $10: 1$ and a column flow rate of $1.1 \mathrm{~cm}^{3} \mathrm{~min}^{-1}$ were applied. The MS parameters were as follows: interface temperature $300{ }^{\circ} \mathrm{C}$; ionization mode EI+; electron energy $70 \mathrm{eV}$. Compounds were identified by using NIST05 library spectra.

\subsection{NMR measurements}

${ }^{1} \mathrm{H}-\mathrm{NMR}$ spectra were measured on a BRUKER DRX 400 instrument operating at $400 \mathrm{MHz}$ and at $25{ }^{\circ} \mathrm{C}$. As a solvent, $99.99 \% \mathrm{D}_{2} \mathrm{O}$ (for the 2-methyl-1,4-benzoquinone only) or $\mathrm{H}_{2} \mathrm{O}: \mathrm{D}_{2} \mathrm{O}=70: 15$ (after addition of the oxidant) was used. The $\mathrm{pH}$ of the solution was kept constant using a $0.50 \mathrm{~mol} \mathrm{dm} \mathrm{m}^{-3}$ phosphate buffer ( $\mathrm{pH}$ 6.3). Chemical shifts were referenced to the water signal. For the evaluation of the spectra, the MestReNova NMR software was used.

\subsection{Cyclic voltammetric measurements}

The cyclic voltammograms of the benzoquinone $(\mathrm{QR}) /$ hydroquinone $\left(\mathrm{QR}-\mathrm{H}_{2}\right)$ redox systems were obtained by means of a Metrohm VA 746 Trace Analyzer equipped with 747 VA Stand controlled by a personal computer. All the measurements were carried out in aqueous solution at slightly acidic or physiological $\mathrm{pH}\left(0.20 \mathrm{~mol} \mathrm{dm}{ }^{-3} \mathrm{Na}_{2} \mathrm{SO}_{4}\right.$ was used as the supporting electrolyte). The solutions were degassed by using argon. The systems were analyzed at 25.0 ${ }^{\circ} \mathrm{C}$ with a three electrode assembly. During the experiments, platinum (Metrohm 6.1204.120) was used as the working electrode. The counter electrode was also a platinum electrode (distributed by ALS Co. Japan), while the reference electrode was a Vycor tip $\mathrm{Ag} / \mathrm{AgCl}$ electrode stored in $3.0 \mathrm{~mol} \mathrm{dm}^{-3} \mathrm{NaCl}$ (BASI Instr. RE-5B, MF-2079). The concentration of benzoquinone was $1 \times 10^{-3} \mathrm{~mol} \mathrm{\textrm {dm } ^ { - 3 }}$. The $\mathrm{pH}$ of the sample was adjusted using 0.05 and 0.005 
mol $\mathrm{dm}^{-3} \mathrm{H}_{2} \mathrm{SO}_{4}$ or $\mathrm{KOH}$ solutions. The volume of the sample was $20.0 \mathrm{~cm}^{3}$. Before each scan, the working electrode was treated with alumina paste $(0.03$ micron ordered from Buehler Company) and the surface was cleaned with the help of sandpaper.

The electrochemical measuring system was calibrated with the $\left[\mathrm{Fe}(\mathrm{CN})_{6}\right]^{3\urcorner} /\left[\mathrm{Fe}(\mathrm{CN})_{6}\right]^{4-}$ redox system. ${ }^{40}$ The potential range was changed between $+800 \mathrm{mV}$ and $-800 \mathrm{mV}$. The voltammograms were recorded at $100 \mathrm{mV} / \mathrm{sec}$ sweep rates. For the analysis of the voltammograms, the CACYVO program was used. The half-wave potential $\left(E_{1 / 2}\right)$ values were calculated based on the following equation:

$$
E_{\mathrm{y}}=\frac{E_{y e}+E_{\mathrm{ye}}}{2}
$$

where $E_{p c}$ and $E_{p a}$ are the cathodic and anodic peak potentials, respectively. Considering that $E_{1 / 2}=E^{0}, E^{0}$ values throughout this work were referenced to NHE taking into account that

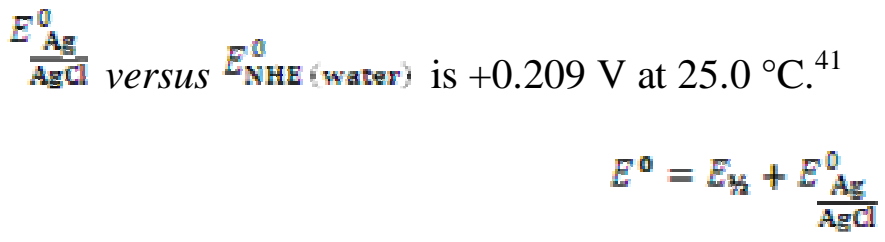

\subsection{Spectrophotometric determination of $p K_{a}$ values}

For the determination of the $\mathrm{p} K_{\mathrm{a}}$ values of the hydroxyquinone derivatives, they were prepared by illuminating $50.0 \mathrm{~cm}^{3}$ of the appropriate $1 \times 10^{-3} \mathrm{~mol} \mathrm{dm}^{-3}$ aqueous solutions of 1,4-benzoquinone and its derivatives with a high intensity Spectroline FC-100/F UV-A lamp emitting at $365 \mathrm{~nm}^{42}$ The photon flux of this lamp is $2.7 \times 10^{17} \mathrm{~s}^{-1}$ in the geometric arrangement used in our experiments. ${ }^{43}$ Photoreactions of these samples result in the formation of colored hydroxyquinones and colorless hydroquinones, the mixture of which seems to be stable for several days even under normal laboratory light conditions. ${ }^{44}$ The formation reaction was followed using a pH-stat titrating system (ABU 91 AUTOBURETTA 
RADIOMETER COPENHAGER) and was completed for all substituted derivatives after a maximum illumination time of 1 hour.

Then, spectrophotometric titrations of $2.50 \mathrm{~cm}^{3}$ samples prepared in this way were performed that is well-known volumes of $0.010 \mathrm{~mol} \mathrm{dm}^{-3} \mathrm{HCl}$ or $0.042 \mathrm{~mol} \mathrm{dm}^{-3} \mathrm{KOH}$ solutions were added to the samples to adjust the $\mathrm{pH}$ of the solution and both the $\mathrm{pH}$ and the absorption spectrum were measured. For every derivative, 15-20 data pairs were measured mainly in the $\mathrm{pH}$ range of the deprotonation process. The MicroMath SCIENTIST ${ }^{39}$ program was used to evaluate the data. The fitted mathematical equation took also the dilution of the samples into account. For a given derivative, 8-14 carefully chosen wavelengths were used for the calculations.

Since the ratio of the two products of the photoreaction was not known, the molar absorption coefficient values for the hydroxyquinone derivatives could not be determined from these data, only the $\varepsilon(\mathrm{QR}-\mathrm{OH}) / \varepsilon\left(\mathrm{QR}-\mathrm{O}^{-}\right)$ratio could be determined.

\subsection{Theoretical calculations}

We performed DFT calculations with the B3LYP exchange-correlation functional. ${ }^{45-47}$ 6$31 \mathrm{G}(\mathrm{d}), 6-31+\mathrm{G}(\mathrm{d}), 6-311+\mathrm{G}(\mathrm{d})$ and $6-311+\mathrm{G}(\mathrm{d}, \mathrm{p})$ were the standard split-valence basis sets. The M06 functional with 6-31G(d) basis set was also used to calibrate the method for the structural parameters. Geometry optimizations were carried out both in vacuo and using the polarizable continuum model (PCM) to account for solvent effects. ${ }^{48,49}$ For PCM calculations, we used Gaussian 09's default Integral Equation Formalism variant (IEFPCM) PCM model. ${ }^{50,51}$ The transition states were optimized by means of the synchronous transit-guided quasi-Newton method. $^{52,53}$ The lack of imaginary frequencies in vibrational spectral calculations were taken to verify that the calculated stationary points on the potential energy surfaces (PES) represented true minima as opposed to transition states (TS). The reactants and 
products are obtained from intrinsic reaction coordinate (IRC) calculations. The relative energies are Gibbs free energies obtained by frequency analysis.

In addition to DFT calculations, in vacuo geometry optimizations were also done using the MP2 method ${ }^{54-58}$ with 6-31G(d) basis set. These calculations were carried out for the minima of the PES but not for the transition states.

All these calculations were carried out using the Gaussian 09 software package. ${ }^{59}$ 


\section{Results and discussion}

The reaction between benzoquinone derivatives and hydrogen peroxide was measured for different substituted benzoquinones. For all measurements, a high excess of $\mathrm{H}_{2} \mathrm{O}_{2}$ ensured the constant concentration for the oxidant. At the same time, the $\mathrm{pH}$ of the solution was kept constant by using a phosphate buffer in high excess compared to the benzoquinone concentration. So, under our experimental conditions, the shape of the kinetic curve only depends on the reaction order with respect to benzoquinone and/or hydroxyquinone concentrations. In the absence of any buffer, the $\mathrm{pH}$ of the solution becomes acidic during the measurements because of the acidic proton in the product hydroxyquinone. E.g., for 1,4benzoquinone, the $\mathrm{pH}$ drops from 6.5 to 3.4 during the reaction.

The formation of hydroxyquinone, a colored product, was shown in all measurements, followed by the decomposition of the hydroxyquinone indicated by the fading of the color formed. The benzoquinones are almost colorless in the visible wavelength range, and the same is true for the final solutions after the decomposition of the hydroxyquinones. So, absorbance-time curves measured in the visible wavelength range are selective for the hydroxyquinone (see: Figure 1). Selected wavelength values for the different derivatives are as follows: $480 \mathrm{~nm}$ for 1,4-benzoquinone, $490 \mathrm{~nm}$ for 2-methy-1,4-benzoquinone, $530 \mathrm{~nm}$ for 2,6-dimethy-1,4-benzoquinone, $510 \mathrm{~nm}$ for 2-chloro-1,4-benzoquinone and $520 \mathrm{~nm}$ for 2,6dichloro-1,4-benzoquinone.

Kinetic curves could be well fitted for all derivatives and under all measured conditions using the following kinetic scheme:

$$
\begin{array}{ll}
\left.\mathrm{QR}-\stackrel{\mathrm{H}_{2} \mathrm{O}_{2}}{\longrightarrow} \text { QR-OH (or QR-O }{ }^{-}\right) & v_{1}=k_{\Psi 1}[\mathrm{QR}] \\
\mathrm{QR}-\mathrm{OH} \stackrel{\mathrm{H}_{2} \mathrm{O}_{2}}{\longrightarrow} \text { Decomposition product(s) } & v_{2}=k_{\Psi 2}[\mathrm{QR}-\mathrm{OH}] \\
& v_{3}=k_{\Psi 3}[\mathrm{QR}-\mathrm{OH}]^{2}
\end{array}
$$


where $\mathrm{QR}$ is an R-substituted 1,4-benzoquinone and $\mathrm{QR}-\mathrm{OH}$ (or $\mathrm{QR}-\mathrm{O}^{-}$) is the corresponding substituted hydroxyquinone. From least squares fitting with MicroMath SCIENTIST, molar absorption coefficients of QR, QR-OH (or $\mathrm{QR}^{-\mathrm{O}^{-}}$) and the decomposition product(s) and $k_{\Psi 1^{-}}$ $k_{\Psi 3}$ apparent rate constants were calculated. The molar absorbance values are $\mathrm{pH}$-dependent in the $\mathrm{pH}$ range around the $\mathrm{p} K_{\mathrm{a}}$ of the hydroxyquinones. The dependence of the apparent rate constants on the concentration of the oxidant and the $\mathrm{pH}$ were studied in detail and used to deduct the full rate equations of the processes. Temperature dependence was also studied to calculate activation parameters.

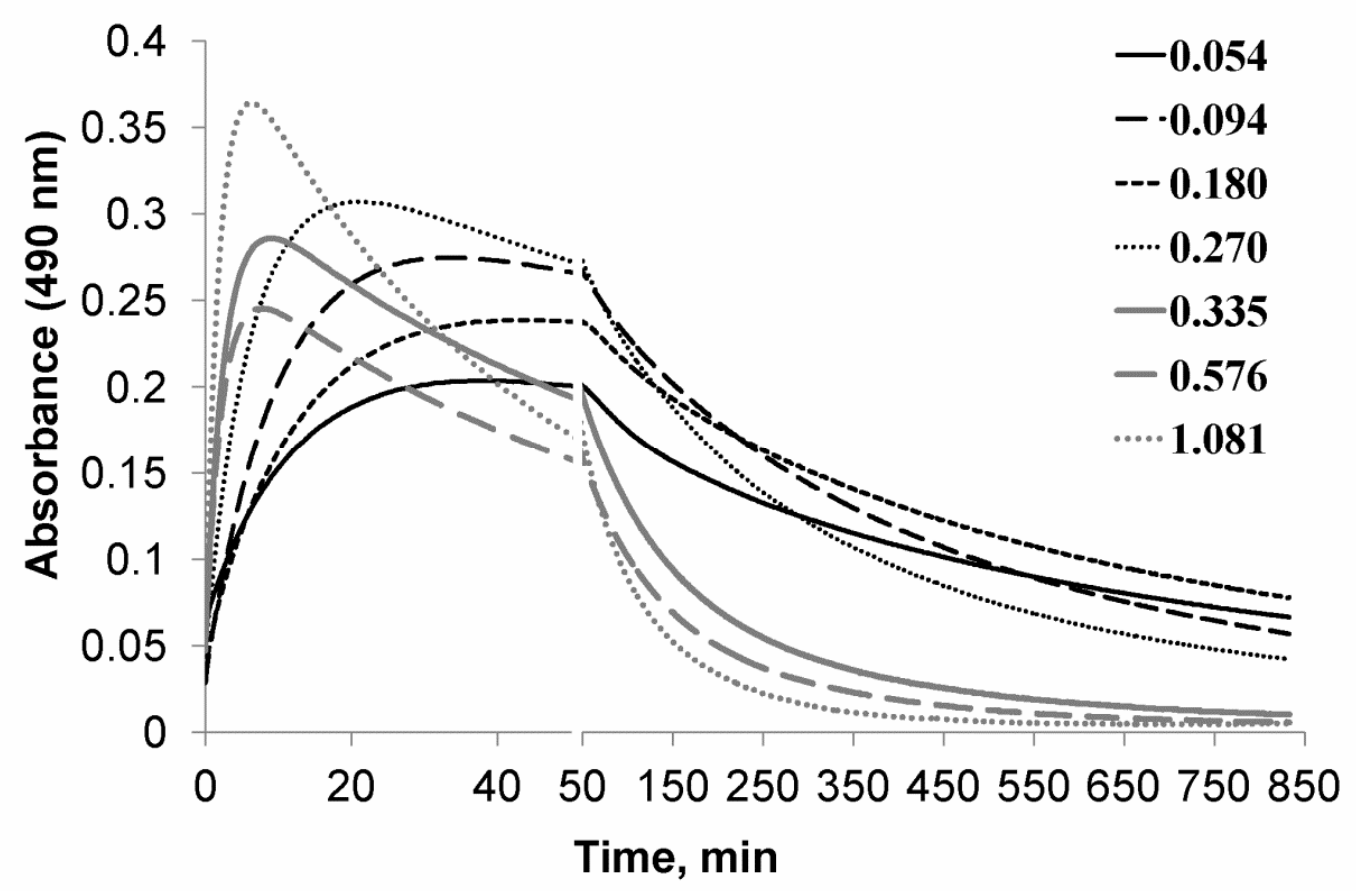

Figure 1: Kinetic curves measured for the reaction between 2-methyl-1,4-benzoquinone (QMe) and hydrogen peroxide at $25.0{ }^{\circ} \mathrm{C} . c(\mathrm{QMe})=9 \times 10^{-4} \mathrm{~mol} \mathrm{dm}^{-3}, \mathrm{pH}=6.6, c\left(\mathrm{H}_{2} \mathrm{O}_{2}\right)$ values in mol $\mathrm{dm}^{-3}$ unit are given in the legends. 
Attempts were made to react 1,4-benzoquinone with periodate ion. Unfortunately, the oxidation reaction did not stop at the hydroxyquinone, so this oxidant was not investigated further.

\subsection{Formation kinetics of the hydroxyquinone}

\subsubsection{Dependence of $k_{\Psi 1}$ on the hydrogen peroxide concentration}

From fitting of the kinetic curves, $k_{\Psi 1}$ apparent rate constants were calculated at many different hydrogen peroxide concentrations for all substituted benzoquinone derivatives. These $k_{\Psi_{1}}$ values were used to determine the rate equation of the benzoquinone oxidation process by observing the dependence of the $k_{\Psi 1}$ values on the hydrogen peroxide concentration. For all derivatives, the data showed a linear relationship with an almost 0 intercept. The process was studied at $c\left(\mathrm{H}_{2} \mathrm{O}_{2}\right)=0$ as well, and some formation of the hydroxyquinone was detected because of the photosensitivity of the aqueous benzoquinone solutions. This was at least three orders of magnitude lower than the initial rate of the oxidation at the lowest hydrogen peroxide concentration studied. To avoid the photoreaction as much as possible, a scanning spectrophotometer was used in single wavelength measurement mode.

The $k_{\Psi 1}$ values are shown in Figure 2 as a function of the concentration of hydrogen peroxide for the 1,4-benzoquinone - hydrogen peroxide system at $\mathrm{pH}$ 6.56-6.59. Molar absorption coefficients for the same $\mathrm{pH}$ value are as follows: $\varepsilon_{480}(\mathrm{Q})=24 \pm 1 \mathrm{dm}^{3} \mathrm{~mol}^{-1} \mathrm{~cm}^{-1}$ and $\varepsilon_{480}\left(\mathrm{Q}-\mathrm{O}^{-}\right)=1703 \pm 88 \mathrm{dm}^{3} \mathrm{~mol}^{-1} \mathrm{~cm}^{-1}$. 


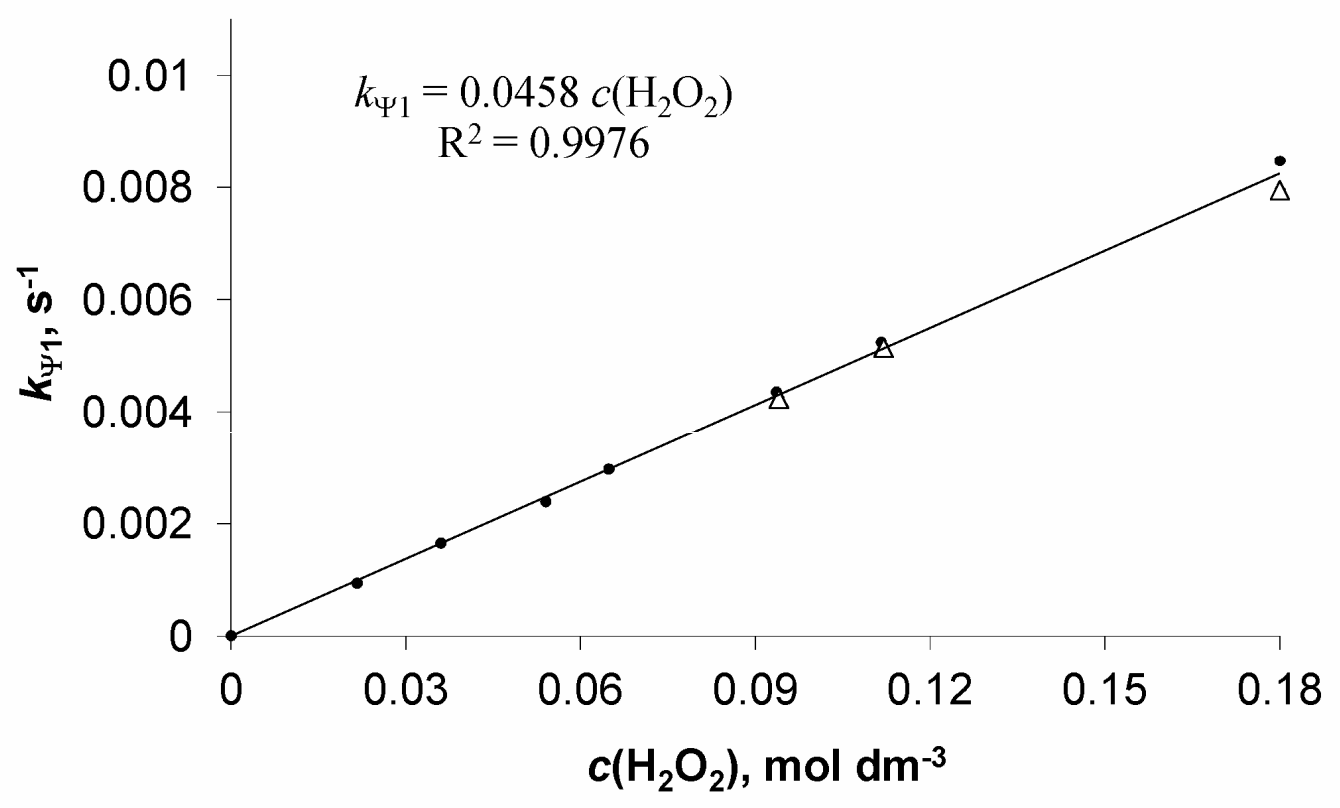

Figure 2: $\mathrm{H}_{2} \mathrm{O}_{2}$ concentration dependence of the $k_{\Psi 1}$ apparent rate constants in the 1,4benzoquinone $(\mathrm{Q})-\mathrm{H}_{2} \mathrm{O}_{2}$ system at $\mathrm{pH}$ 6.56-6.59 and $25.0{ }^{\circ} \mathrm{C}$. Small $\operatorname{dots}(\bullet)$ are from spectrophotometric and large triangles $(\Delta)$ are from stopped-flow experiments.

The same kinds of experiments were performed for 2-methyl-1,4-benzoquinone and 2chloro-1,4-benzoquinone. In all cases, the same linear hydrogen peroxide concentration dependence of the $k_{\Psi 1}$ values was found (see: Tables S1-S3 and Figures S1-S3 in the Supplementary Information). 2,6-Dimethyl-1,4-benzoquinone was also reacted with $\mathrm{H}_{2} \mathrm{O}_{2}$, but there was no measureable change after $20 \mathrm{~min}$ even and at the highest hydrogen peroxide concentrations, $c\left(\mathrm{H}_{2} \mathrm{O}_{2}\right)=0.58 \mathrm{~mol} \mathrm{dm}^{-3}$ and $c\left(\mathrm{H}_{2} \mathrm{O}_{2}\right)=2.3 \mathrm{~mol} \mathrm{dm}^{-3}$.

\subsubsection{Dependence of $k_{\Psi 1}$ on the hydrogen ion concentration}


In the case of 1,4-benzoquinone and 2-methyl-1,4-benzoquinone, $\mathrm{pH}$ dependent kinetic curves were also measured. For the experiments using the methyl derivative, $c\left(\mathrm{H}_{2} \mathrm{O}_{2}\right)$ was $0.58 \mathrm{~mol}$ $\mathrm{dm}^{-3}$ and $c$ (2-methyl-1,4-benzoquinone) was $0.95 \mathrm{mmol} \mathrm{dm}{ }^{-3}$. The apparent rate constant decreased an order of magnitude when the $\mathrm{pH}$ was decreased by 1 unit (at $\mathrm{pH} 6.59, k_{\Psi 1}$ was $(8.03 \pm 0.06) \times 10^{-3} \mathrm{~s}^{-1}$ and at $\mathrm{pH} 5.69, k_{\Psi 1}$ was $\left.(9.5 \pm 0.2) \times 10^{-4} \mathrm{~s}^{-1}\right)$. A similar $\mathrm{pH}$ dependence was found for the unsubstituted 1,4-benzoquinone oxidation reaction.

Based on these data, both the 2-methyl and the unsubstituted derivative show the same inverse first order hydrogen ion concentration dependence as the 2,6-dichloro derivative. ${ }^{24}$ The $\mathrm{pH}$ dependence of the 2-chloro derivative was not checked but assumed to be the same:

$$
v_{1} 1=k_{1}\left(1[\mathrm{QR}]=k_{\downarrow} 1[\mathrm{QR}]\left[\mathrm{H}_{4} 2 \mathrm{O}_{4} 2\right] /\left[\mathrm{H}^{\mathrm{T}}+\right] \quad\right. \text { that is }
$$

$k_{1} 1=k_{1}\left(1\left(\left[\mathbf{H}^{*}+1\right) /\left[\mathbf{H}_{1} 2 O_{1} 2\right]\right.\right.$

Based on this equation, $k_{1}$ values for the different substituted derivatives were calculated by multiplying the slopes of the $k_{\Psi 1}$ versus $c\left(\mathrm{H}_{2} \mathrm{O}_{2}\right)$ values with the hydrogen ion concentration of the solutions (when the $\mathrm{pH}$ is constant), or, by finding the slopes of the $k_{\Psi 1} \times\left[\mathrm{H}^{+}\right]$versus $c\left(\mathrm{H}_{2} \mathrm{O}_{2}\right)$ fittings (Figures $\mathrm{S} 2$ and $\mathrm{S} 3$ in the Supplementary Information). Calculated $k_{1}$ values for different derivatives are shown in Table 1 together with some other measured parameters for the different derivatives.

Table 1: $k_{1}, \mathrm{p} K_{\mathrm{a}}(\mathrm{QR}-\mathrm{OH})$ and $E^{0}\left(\mathrm{QR} / \mathrm{QR}-\mathrm{H}_{2}\right)$ values for different 1,4-benzoquinone derivatives at $25.0^{\circ} \mathrm{C}$

\begin{tabular}{|c|c|c|c|}
\hline Derivative & $\boldsymbol{k}_{\mathbf{1}}$ & $\mathbf{p} \boldsymbol{K}_{\mathbf{a}}(\mathbf{Q R}-\mathbf{O H})$ & $\boldsymbol{E}^{\mathbf{0}}\left(\mathbf{Q R} / \mathbf{Q R}-\mathrm{H}_{2}\right)$ at $\mathbf{p H} 5.1$ \\
& $\left(\mathbf{s}^{\mathbf{- 1}}\right)$ & & $(\mathbf{V})$ \\
\hline 2-methyl-1,4- & $(3.46 \pm 0.01) \times 10^{-9}$ & $4.5 \pm 0.4$ & 0.059 \\
benzoquinone (QMe) & & & \\
\hline
\end{tabular}




\begin{tabular}{|c|c|c|c|}
\hline 1,4-benzoquinone (Q) & $(1.23 \pm 0.02) \times 10^{-8}$ & $3.4 \pm 0.1$ & 0.120 \\
\hline 2-chloro-1,4- & $(1.49 \pm 0.03) \times 10^{-7}$ & $2.8 \pm 0.6$ & 0.188 \\
benzoquinone & & & \\
\hline 2,6-dichloro-1,4- & $2.7 \times 10^{-7} *$ & $1.8 \pm 0.6$ & 0.244 \\
benzoquinone & & & \\
\hline
\end{tabular}

* From Ref. 24.

The rate equation described by equation (6) can be explained by the mechanism that was proposed for the 2,6-dichloro-benzoquinone - hydrogen peroxide reaction: ${ }^{24}$

$$
\begin{aligned}
& \mathrm{H}_{2} \mathrm{O}_{2} \stackrel{\mathrm{K}_{2}\left(\mathrm{H}_{2} \mathrm{O}_{2}\right)}{=} \mathrm{H}^{*}+\mathrm{HO}_{2}^{-} \quad \text { fast pre-equilibrium; } \\
& \left.\mathrm{QR}+\mathrm{HO}_{2}^{-} \stackrel{k_{\mathrm{b}}}{\longrightarrow} \mathrm{QR}-\mathrm{OH}+\mathrm{H}_{2} \mathrm{O}_{2}\right)=\frac{\left[\mathrm{H}^{-}\right]\left[\mathrm{HO}_{2}^{-}\right]}{\left[\mathrm{H}_{2} \mathrm{O}_{2}\right]} \\
& \text { (or QR-O } \left.-\mathrm{O}^{-}+\mathrm{H}_{2} \mathrm{O}\right) \quad \text { rate determining step }
\end{aligned}
$$

Based on this mechanism, the rate constant of the rate determining step, $k_{\mathrm{b}}$ can be calculated as follows:

$$
k_{1}=K_{\mathrm{a}}\left(\mathrm{H}_{2} \mathrm{O}_{2}\right) k_{\mathrm{b}} \quad \text { that is } \quad k_{\mathrm{b}}=\frac{k_{1}}{K_{\mathrm{a}}\left(\mathrm{H}_{2} \mathrm{O}_{2}\right)}
$$

To support this assumed mechanism further, activation parameters for the rate determining step (8) of the 2-methyl-1,4-benzoquinone - hydrogen peroxide reaction were determined both experimentally and by DFT calculations.

\subsubsection{Temperature dependence of hydroxyquinone formation}

To determine the activation parameters for the rate determining step of the mechanism described by equations (7) and (8), temperature dependent kinetic curves were measured in the 2-methyl-1,4-benzoquinone - hydrogen peroxide system. The temperature range for these measurements was $10-40{ }^{\circ} \mathrm{C}$. In the case of the temperature dependent experiments, $c(\mathrm{QMe})=$ $9.5 \times 10^{-4} \mathrm{~mol} \mathrm{dm}{ }^{-3}, c\left(\mathrm{H}_{2} \mathrm{O}_{2}\right)=0.58 \mathrm{~mol} \mathrm{dm}^{-3}$ and $\mathrm{pH}=6.39$ were used. Kinetic curves 
measured at different temperatures are shown in Figure 3. It is clear that both the formation and the decomposition reaction of the hydroxyquinone become faster with increasing temperature.

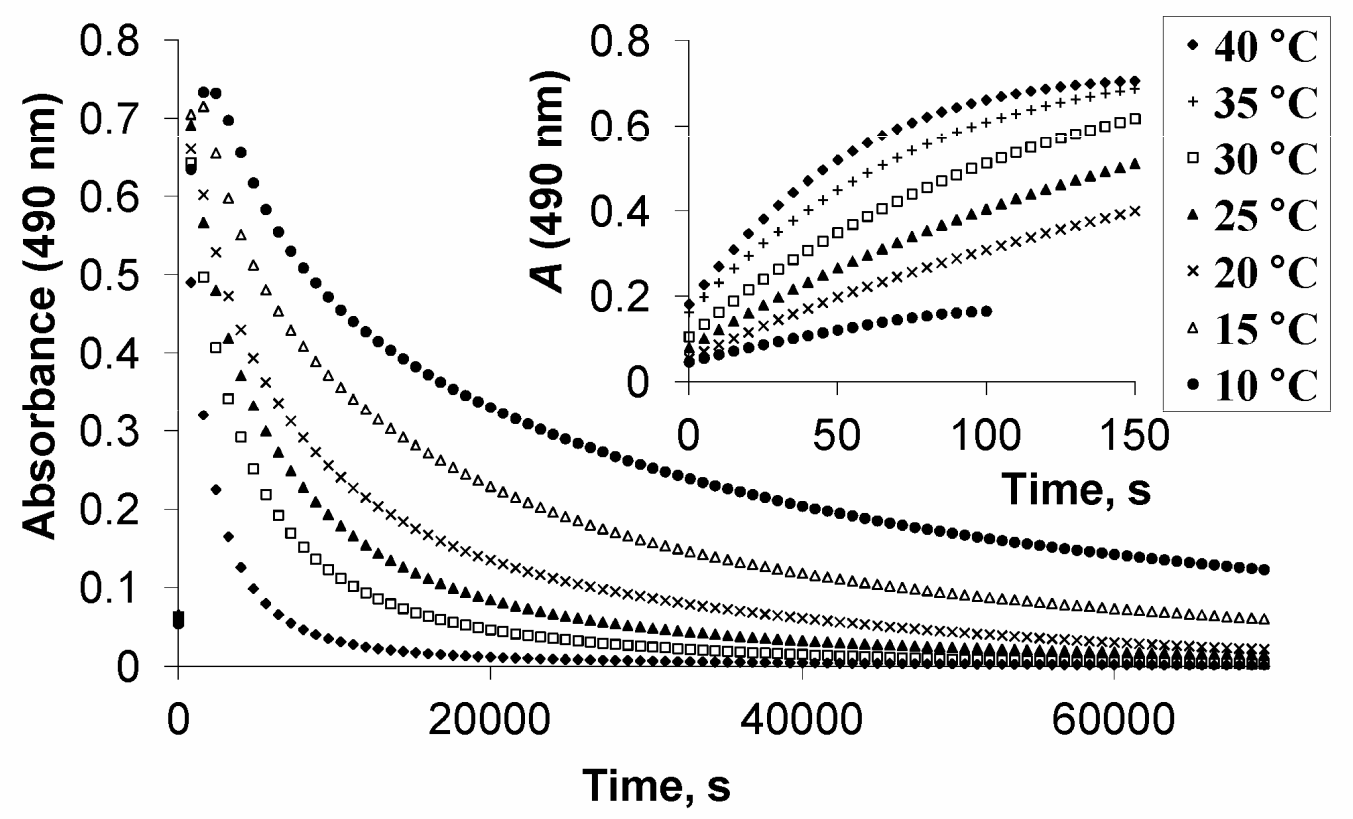

Figure 3: Kinetic curves measured at different temperatures for the reaction between 2methyl-1,4-benzoquinone and hydrogen peroxide. $c(\mathrm{QMe})=9.5 \times 10^{-4} \mathrm{~mol} \mathrm{dm}^{-3}, c\left(\mathrm{H}_{2} \mathrm{O}_{2}\right)$

$$
=0.58 \mathrm{~mol} \mathrm{dm}^{-3}, \mathrm{pH}=6.39
$$

All curves were fitted as described earlier to determine temperature dependent $k_{\Psi 1}$ values. Using these, $k_{\mathrm{b}}$ values were calculated using equations (6) and (9) together with the $\mathrm{p} K_{\mathrm{a}}\left(\mathrm{H}_{2} \mathrm{O}_{2}\right)$ values known from the literature. ${ }^{60}$

Using these temperature dependent $k_{\mathrm{b}}$ values, Arrhenius and Eyring plots were drawn to determine the activation parameters, namely the $E_{\mathrm{a}}$ activation energy, $\Delta G^{*}$ Gibbs energy (or 
free energy) of activation, $\Delta H^{\mathbb{1}}$ enthalpy of activation and $\Delta S^{\mathbb{t}}$ entropy of activation. The data found are as follows for the 2-methyl-1,4-benzoquinone: $E_{\mathrm{a}}=18.4 \pm 0.4 \mathrm{~kJ} \mathrm{~mol}^{-1}, \Delta H^{ \pm}=$ $15.9 \pm 0.4 \mathrm{~kJ} \mathrm{~mol}^{-1}$ and $\Delta S^{\mp}=-129 \pm 1 \mathrm{~J} \mathrm{~mol}^{-1} \mathrm{~K}^{-1}$. Activation parameters were determined using the non-linearized forms of the Arrhenius and Eyring equations and using a relative weighing $\left(1 / \mathrm{R}^{2}\right)$ in SCIENTIST. These parameters are in good agreement with the activation parameters calculated by theoretical methods supporting the assumed mechanism.

The ratio of the standard deviations for $\Delta H^{ \pm}\left( \pm 420 \mathrm{~J} \mathrm{~mol}^{-1}\right)$ and $\Delta \varsigma^{ \pm}\left( \pm 1.41 \mathrm{~J} \mathrm{~mol}^{-1}\right.$ $\mathrm{K}^{-1}$ ), as expected, ${ }^{61}$ gives the average temperature of the measurements. $\Delta G^{\frac{1}{2}}$ values for the 10-40 ${ }^{\circ} \mathrm{C}$ temperature range are between 52.4 and $56.3 \mathrm{~kJ} \mathrm{~mol}^{-1}$ (all values are listed in the Supplementary Information section in Table S4). The reaction has a large entropy contribution to the $\Delta G^{\ddagger}$ values. Linearized Eyring plot of the data is shown in Figure 4.

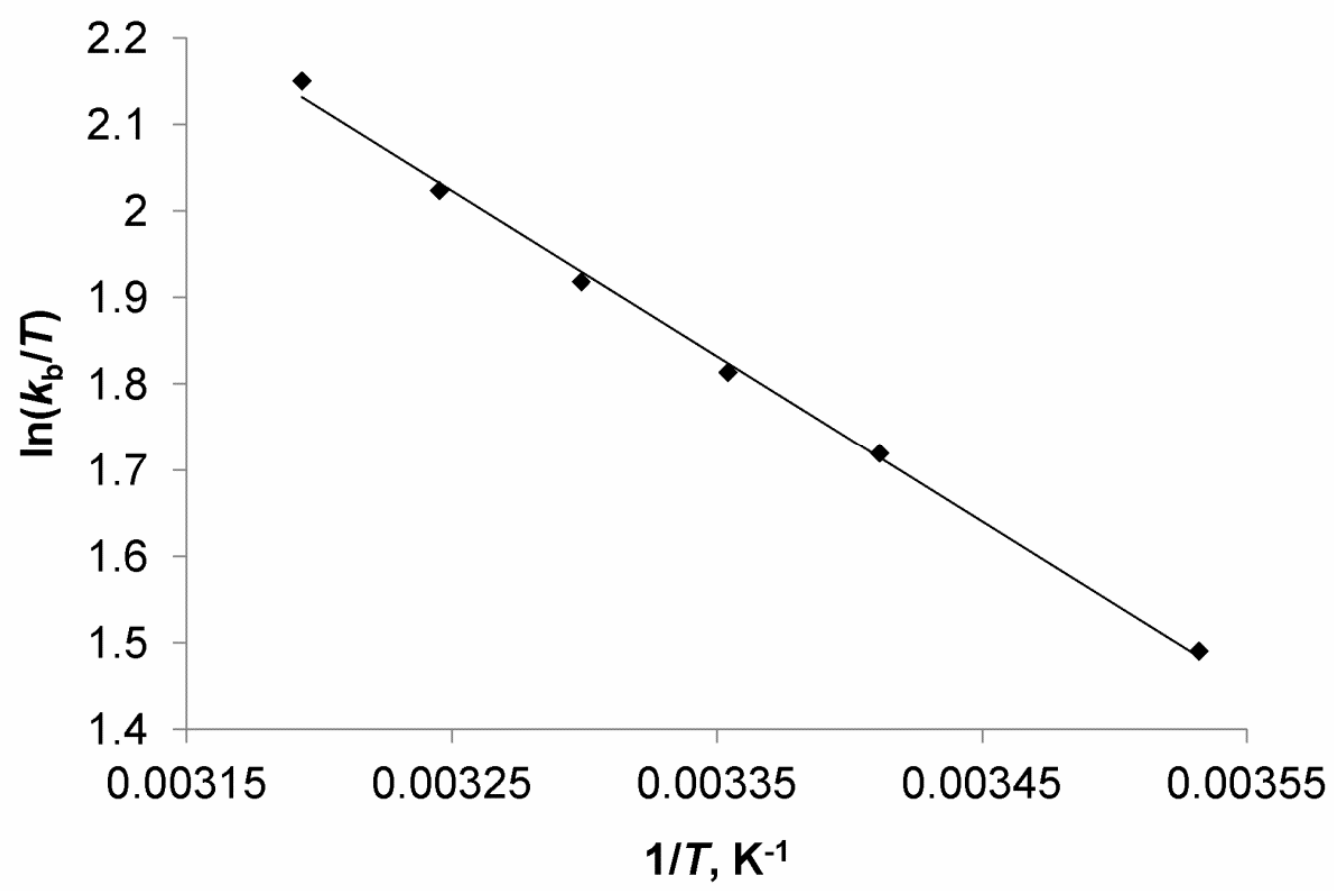


Figure 4: Plot of the linearized Eyring equation for the $\mathrm{QMe}+\mathrm{HO}_{2}^{-}-\stackrel{k_{b}}{\longrightarrow} \mathrm{QMe}-\mathrm{O}^{-}$

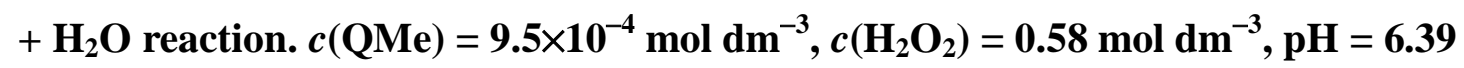

Also, the position of the hydroxyl group in the hydroxyquinone is a question in the case of the methyl (or any mono-substituted derivative) because the three available positions (numbered 3, 5 and 6 on the quinone ring) are different. To find out the structure of the hydroxyquinone formed during the reaction, ${ }^{1} \mathrm{H}-\mathrm{NMR}$ measurements were performed. Based on the spectra, it seems more likely that the hydroxylation happens in the $5^{\text {th }}$ or $6^{\text {th }}$ position and not in the neighboring position to the methyl group. This finding is in good agreement with the results of the theoretical calculations as will be discussed later.

\subsubsection{Mechanism of the formation of hydroxyquinone}

We have studied the mechanism of the formation of the hydroxyquinones using DFT and MP2 methods. B3LYP and M06 functionals were also tested to find out the structural parameters of the starting reagent benzoquinone. We concluded that there is no significant difference between the structural parameters calculated by the two functionals, so, in our further calculations for investigating the possible mechanisms, only the B3LYP functional was used. The B3LYP functional was earlier proved to be a useful level for the calculations in studying the reactions between variously substituted quinones and hydrogen peroxide. ${ }^{62,63} \mathrm{We}$ used the $6-311+G(d, p)$ basis set in our calculations to obtain the mechanism of the reaction between benzoquinone (Q) and $\mathrm{H}_{2} \mathrm{O}_{2}$. Geometry optimizations were carried out using the default polarizable continuum model (PCM) of the Gaussian 09 software. The stationary points were identified by frequency analysis and with IRC calculations, too. (In vacuo results obtained with smaller basis sets, such as $6-31 \mathrm{G}(\mathrm{d})$ and $6-31+\mathrm{G}(\mathrm{d})$ at B3LYP level, and also 
the results of the MP2 calculations with $6-31 \mathrm{G}(\mathrm{d})$ basis set are collected in the Supplementary Information.)

The reaction of $\mathrm{Q}$ with $\mathrm{H}_{2} \mathrm{O}_{2}$ did not give any product, while the coordination of $\mathrm{OOH}^{-}$to the $\mathrm{C} 1$ carbon atom of $\mathrm{Q}$ resulted in an adduct $\left(\mathrm{Q}-\mathrm{OOH}^{1}\right)$. (Note that this structure could not be found as an intermediate using smaller basis sets.) From the Q- $\mathrm{OOH}^{1}$ structure, we found another form $\left(\mathrm{Q}-\mathrm{OOH}^{2}\right)$, where the $\mathrm{OOH}^{-}$is coordinated to $\mathrm{C} 2$ of $\mathrm{Q}$ : there is an intramolecular hydrogen bond in this case. The structures of $\mathrm{Q}-\mathrm{OOH}^{1}$ and $\mathrm{Q}-\mathrm{OOH}^{2}$ can be seen in Figure 5. The energy barrier of the $\mathrm{Q}-\mathrm{OOH}^{1} \rightarrow \mathrm{Q}-\mathrm{OOH}^{2}$ realignment is $21.8 \mathrm{~kJ}$ $\mathrm{mol}^{-1}$, as shown by $\mathrm{TS}_{1}$ in Figure 6.
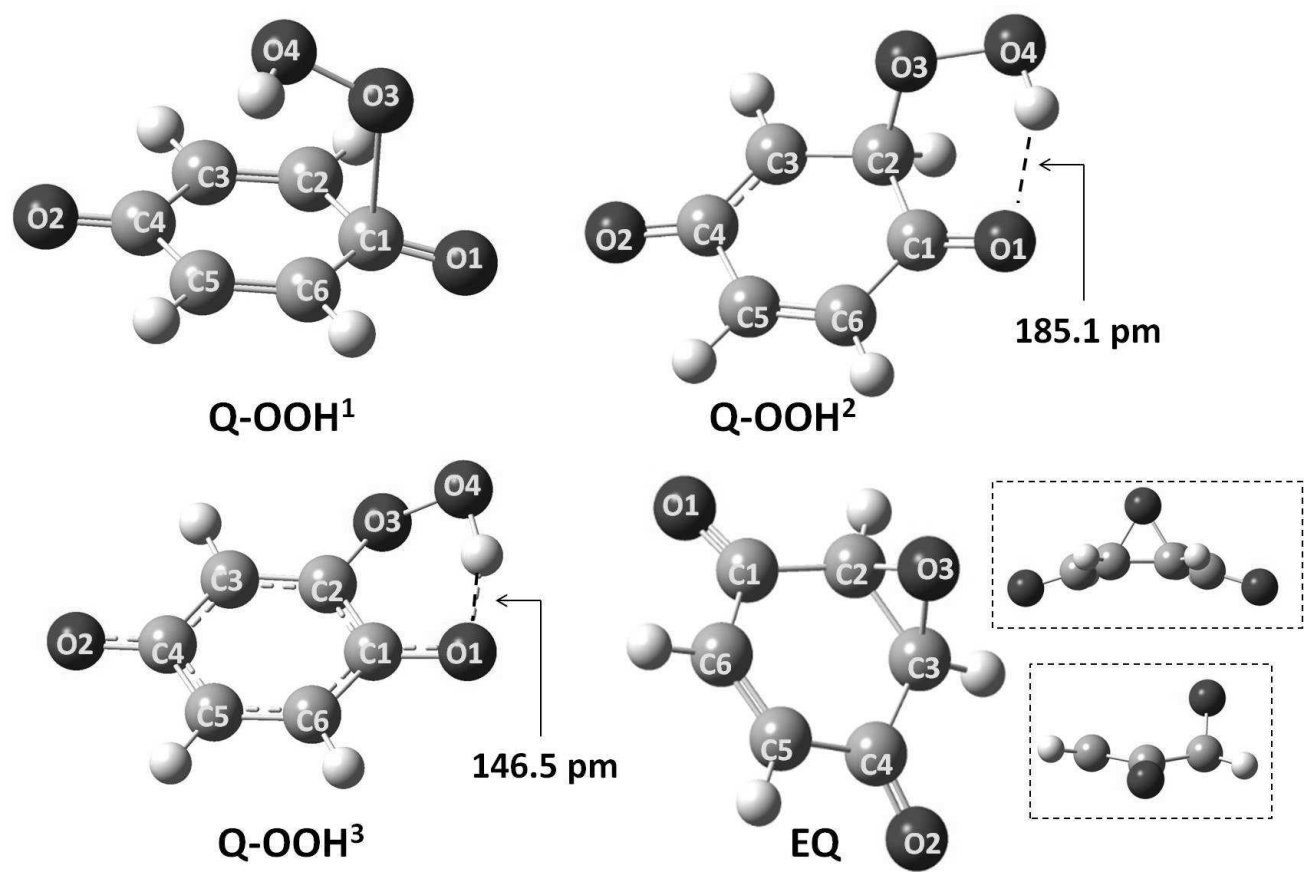

Figure 5: The structures of $\mathrm{Q}-\mathrm{OOH}^{1}, \mathrm{Q}-\mathrm{OOH}^{2}, \mathrm{Q}-\mathrm{OOH}^{3}$ and $\mathrm{EQ}$. The inserted pictures show the bent ring of EQ from different view. 


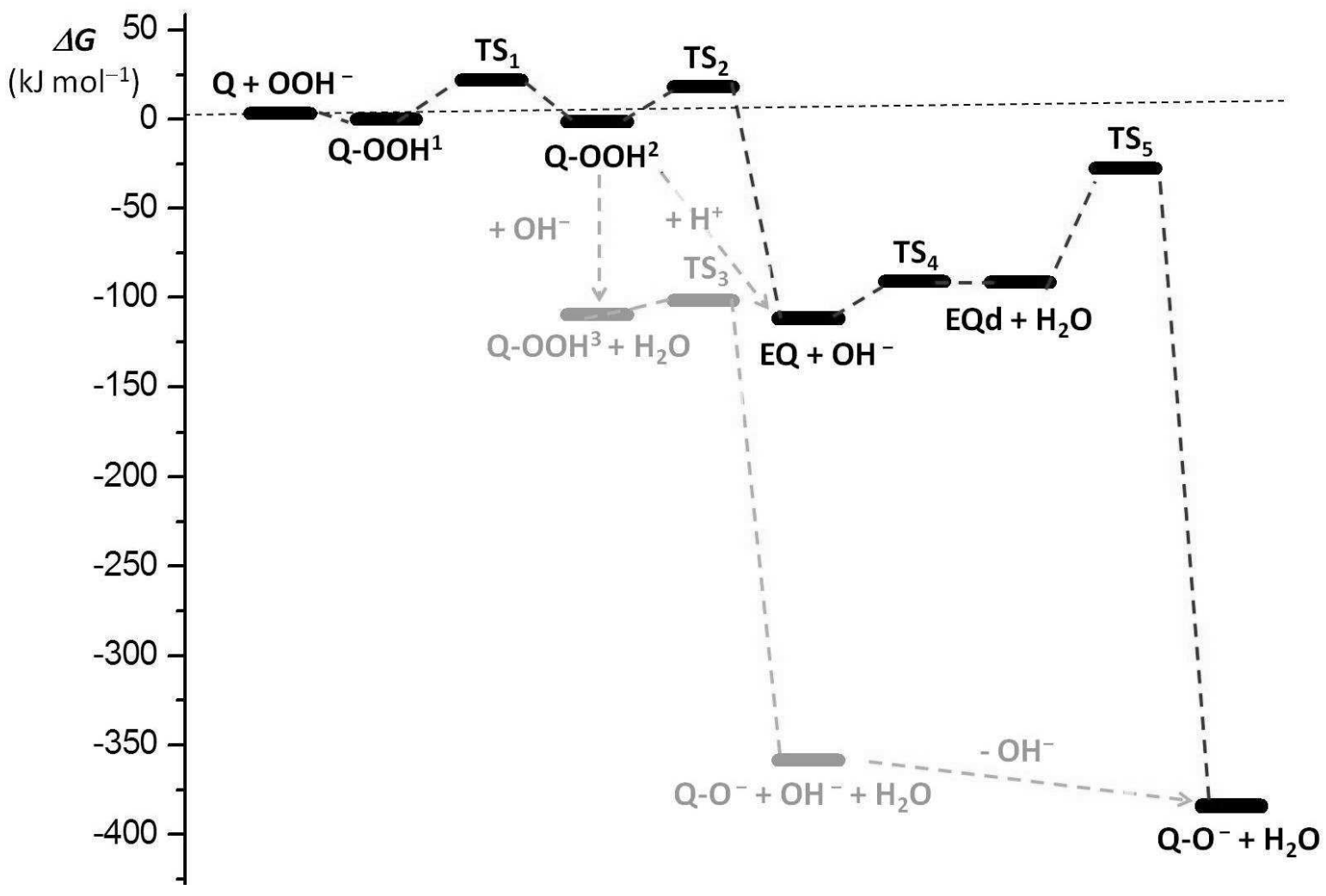

Figure 6. Energy profile of the possible pathways of formation of hydroxyquinone.

From both forms $\left(\mathrm{Q}-\mathrm{OOH}^{1}\right.$ and $\left.\mathrm{Q}-\mathrm{OOH}^{2}\right)$, we investigated three possibilities of chemical reactions: the $\mathrm{O}-\mathrm{O}$ peroxo bond breaking, the protonation of the outer oxygen atom (O4 in Figure 5), and the deprotonation of the $\mathrm{C} 2$ atom. We found that there is no minimum starting from $\mathrm{Q}-\mathrm{OOH}^{1}$, while the calculations starting from $\mathrm{Q}-\mathrm{OOH}^{2}$ show different minima, i.e. different pathways, which are shown in Figure 6. It is a bit surprising that $\mathrm{C} 2$ can be spontaneously deprotonated by an $\mathrm{OH}^{-}$ion, which results in a planar aromatic ring $\left(\mathrm{Q}-\mathrm{OOH}^{3}\right.$ in Figure 5). However, this pathway seems to be unrealistic (and so, drawn with grey in Figure 6) when the size of the calculated system is increased by adding two water molecules to the $\mathrm{OH}^{-}$. We found that, in this case, the deprotonation of $\mathrm{Q}-\mathrm{OOH}^{2}$ is not a spontaneous process because of the stabilization of the $\mathrm{OH}^{-}$ion $\left(\mathrm{OH}^{-}+2 \mathrm{H}_{2} \mathrm{O}\right.$ cluster) i.e. decrease of the hard character of the $\mathrm{OH}^{-}$. In this case, the energy barrier is $34.4 \mathrm{~kJ} \mathrm{~mol}^{-1}$, in contrast with the barrierless reaction in the absence of water molecules. From $\mathrm{Q}-\mathrm{OOH}^{3}$, the deprotonated 
hydroxyquinone $\left(\mathrm{Q}-\mathrm{O}^{-}\right)$can be formed through a small energy barrier $\left.\triangle G^{\mathbb{I}}=8.3 \mathrm{~kJ} \mathrm{~mol}^{-1}\right)$, as shown by $\mathrm{TS}_{3}$ in Figure 6.

In the other pathway, the peroxo bond breaking of $\mathrm{Q}-\mathrm{OOH}^{2}$ results in the formation of an epoxide (EQ, see Figure 5), where the activation barrier is $19.3 \mathrm{~kJ} \mathrm{~mol}^{-1}$, as shown by $\mathrm{TS}_{2}$ in Figure 6. However, when the size of the calculated system is increased by adding two water molecules to $\mathrm{Q}-\mathrm{OOH}^{2}\left(\mathrm{Q}-\mathrm{OOH}^{2}+2 \mathrm{H}_{2} \mathrm{O}\right.$ coordinated to the $\mathrm{O} 4$ oxygen atom), the peroxo bond breaking shows a much lower energy barrier $\left(4.0 \mathrm{~kJ} \mathrm{~mol}^{-1}\right)$. It indicates that, in reality, the peroxo bond breaking inside the $\mathrm{Q}-\mathrm{OOH}^{2}$ molecule is more probable then the deprotonation of $\mathrm{C} 2$. This phenomenon supports the pathway through EQ. EQ is formed when the remaining oxygen $(\mathrm{O} 3)$ coordinates to the $\mathrm{C} 3$ after the peroxo bond breaking. The quinone ring of EQ is strongly bent and this might be called a boat conformation because of the similarity of cyclohexane conformations. It is worth mentioning that a protonation of the outer oxygen atom $(\mathrm{O} 4)$ can indicate a barrierless peroxo bond breaking in $\mathrm{Q}-\mathrm{OOH}^{2}$ yielding $\mathrm{EQ}$ again. The significance of this pathway depends on the experimental conditions $(\mathrm{pH}$ of the solution). The main structural parameters of $\mathrm{Q}, \mathrm{Q}-\mathrm{OOH}^{\mathrm{x}}(\mathrm{x}=1-3)$ and $\mathrm{EQ}$ are summarized in Table S6 of the Supplementary Information.

EQ can then be deprotonated on $\mathrm{C} 2$ or $\mathrm{C} 3$ by an $\mathrm{OH}^{-}$ligand with an activation barrier of $20.8 \mathrm{~kJ} \mathrm{~mol}^{-1}$, as shown by $\mathrm{TS}_{4}$ in Figure 6. From this deprotonated EQ derivative (EQd), Q- $\mathrm{O}^{-}$is obtained when the epoxide ring opens $\left(\triangle G^{\mathrm{I}}=63.7 \mathrm{~kJ} \mathrm{~mol}^{-1}\right)$, as shown by $\mathrm{TS}_{5}$ in Figure 6. Using smaller basis sets, the calculated activation barriers were found to be somewhat smaller (see: Tables S9 in the Supplementary Information). The other possibility from EQ would be the protonation of EQ on the oxygen of the epoxide unit $(\mathrm{O} 3)$. However, based on our calculations, this cannot happen: there was no minimum found.

In the energy profile of the full mechanism (Figure 6), it can be seen that the formations of EQ and $\mathrm{Q}-\mathrm{O}^{-}$are extremely favored thermodynamically. The stationary points 
of the rate determining step, i.e. the epoxide ring opening, can be seen in Figure 7. All structures (xyz coordinates and pictures) of the full mechanism and IRC pathways can be seen in the Supplementary Information.

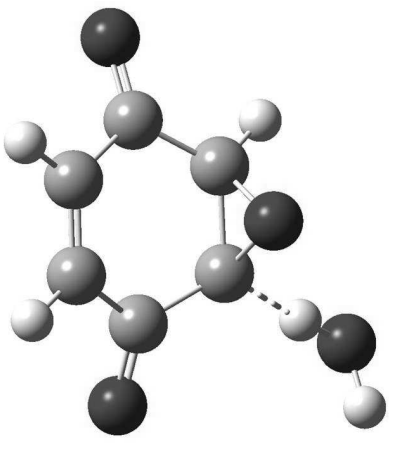

$\mathrm{EQd}+\mathrm{H}_{2} \mathrm{O}$

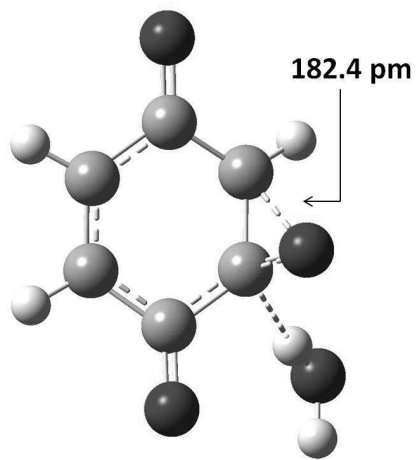

$\mathrm{TS}_{5}$

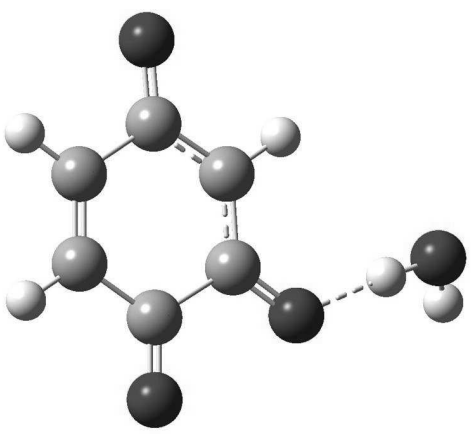

$\mathrm{Q}-\mathrm{O}^{-}+\mathrm{H}_{2} \mathrm{O}$

Figure 7. The reactant $\left(\mathrm{EQd}+\mathrm{H}_{2} \mathrm{O}\right)$, transition state $\left(\mathrm{TS}_{5}\right)$ and product $\left(\mathrm{Q}-\mathrm{O}^{-}+\mathrm{H}_{2} \mathrm{O}\right)$ of the rate determining step (epoxide ring opening).

The EQ intermediate is a stable form, so there is a straightforward deprotonation of EQ and (finally) ring opening from this point. The very high negative value determined experimentally for the entropy of activation is also in conceptual agreement with the formation of an epoxide structure in the transition state, as this process certainly means a major loss of translational degrees of freedom.

We also carried out calculations for the 2-methyl-1,4-benzoquinone (QMe) derivative. At first, the relative energies of the possible isomers were checked (Figure 8). The intermediates for all possible pathways can be found in the Supplementary Information as Figure S8. 


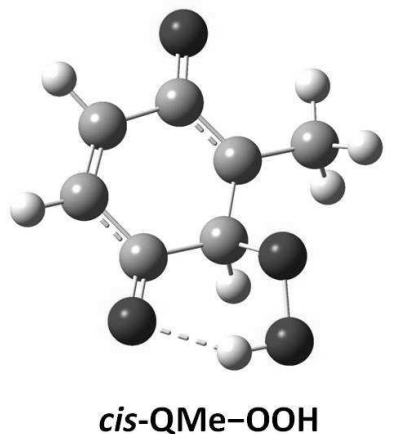

$14.9 \mathrm{~kJ} \mathrm{~mol}^{-1}$

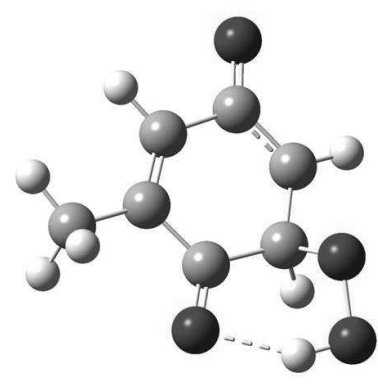

tr-QMe $\mathrm{QMOH}^{1}-\mathrm{OOH}$

$0.0 \mathrm{~kJ} \mathrm{~mol}^{-1}$

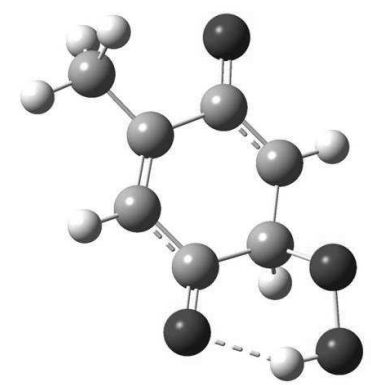

tr-QMe ${ }^{2}-\mathrm{OOH}$

$5.9 \mathrm{~kJ} \mathrm{~mol}^{-1}$

\section{Figure 8. The structures and the relative energies of the possible isomers of the}

\section{QMe-OOH complex.}

It can be seen that the cis isomer is not favored at all. Therefore, no further calculations were run for that. We found that the mechanism is the same for the two transQMe isomers ( $t r-\mathrm{QMe}^{1}$ and $t r-\mathrm{QMe}^{2}$ ) as for unsubstituted $\mathrm{Q}$. We were mainly interested in the activation barrier of the rate-determining step (epoxide ring opening) to make a comparison with the theoretical calculations for $\mathrm{Q}$ and with the experimental data. It can be seen that the activation barrier of the ring opening is higher in the case of methyl derivatives than for Q (see Table 2). It is in good agreement with the experimental data (see $k_{1}$ values in Table 1), which show that the process is a bit slower for the methyl derivative. Experimentally, we found that the $\Delta G^{ \pm}$values for the methyl derivative are between $52.4 \mathrm{~kJ}$ $\mathrm{mol}^{-1}$ and $56.3 \mathrm{~kJ} \mathrm{~mol}^{-1}$ for the $10-40^{\circ} \mathrm{C}$ temperature range (Table $\mathrm{S} 4$ in the Supplementary Information). These values are in acceptable agreement with the calculated one (Table 2).

The unfavored formation of the cis isomer may also explain why no hydroxylated product was detected for 2,6-dimethyl-1,4-benzoquinone experimentally: in this case, both available positions are cis to one of the methyl substituents.

Table 2. The activation Gibbs free energies of the $Q$ and trans-QMe complexes. 


\begin{tabular}{|c|c|c|c|}
\hline \multirow{2}{*}{} & \multicolumn{3}{|c|}{$\Delta G^{ \pm}\left(\mathbf{k J ~ m o l}^{\mathbf{- 1}}\right)$} \\
\cline { 2 - 4 } & Peroxo bond & Deprotonation of & Epoxide ring \\
breaking & the epoxide form & opening \\
\hline $\mathbf{Q}$ & 19.3 & 20.8 & 63.7 \\
\hline $\operatorname{tr}-\mathbf{Q M e}^{\mathbf{1}}$ & 18.9 & 25.6 & 74.8 \\
\hline $\operatorname{tr}-\mathbf{Q M e}^{\mathbf{2}}$ & 14.8 & 25.5 & 78.4 \\
\hline
\end{tabular}

\subsubsection{The effect of substituents on the reaction rate}

The quinones chosen for the kinetic investigation include unsubstituted 1,4-benzoquinone (Q), its derivatives with electron donating (methyl) substituents and derivatives with electron withdrawing (chloro) groups. As it can be seen from the data in Table 1, the electron donating or -withdrawing properties of the substituents significantly change the rate constant of the benzoquinone - hydrogen peroxide reaction. Moreover, the two other measured parameters, namely the $\mathrm{p} K_{\mathrm{a}}$ values of the hydroxyquinone and the redox potentials of the benzoquinone/hydroquinone systems also correlate with the electron donating or withdrawing properties of the substituents. Hammett substituent constants for substituted benzoquinones are not known from the literature yet. However, the $\mathrm{p} K_{\mathrm{a}}$ values for hydroxyquinones, the redox potential values for the quinone/hydroquinone redox systems and the logarithms of the $k_{1}$ rate constant values for the benzoquinone - hydrogen peroxide reactions show a linear correlation indicating that these values are influenced by a common structural factor, which most probably arises from the electron donating or -withdrawing properties of the substituents. The linear correlation is demonstrated in Figure 9. 


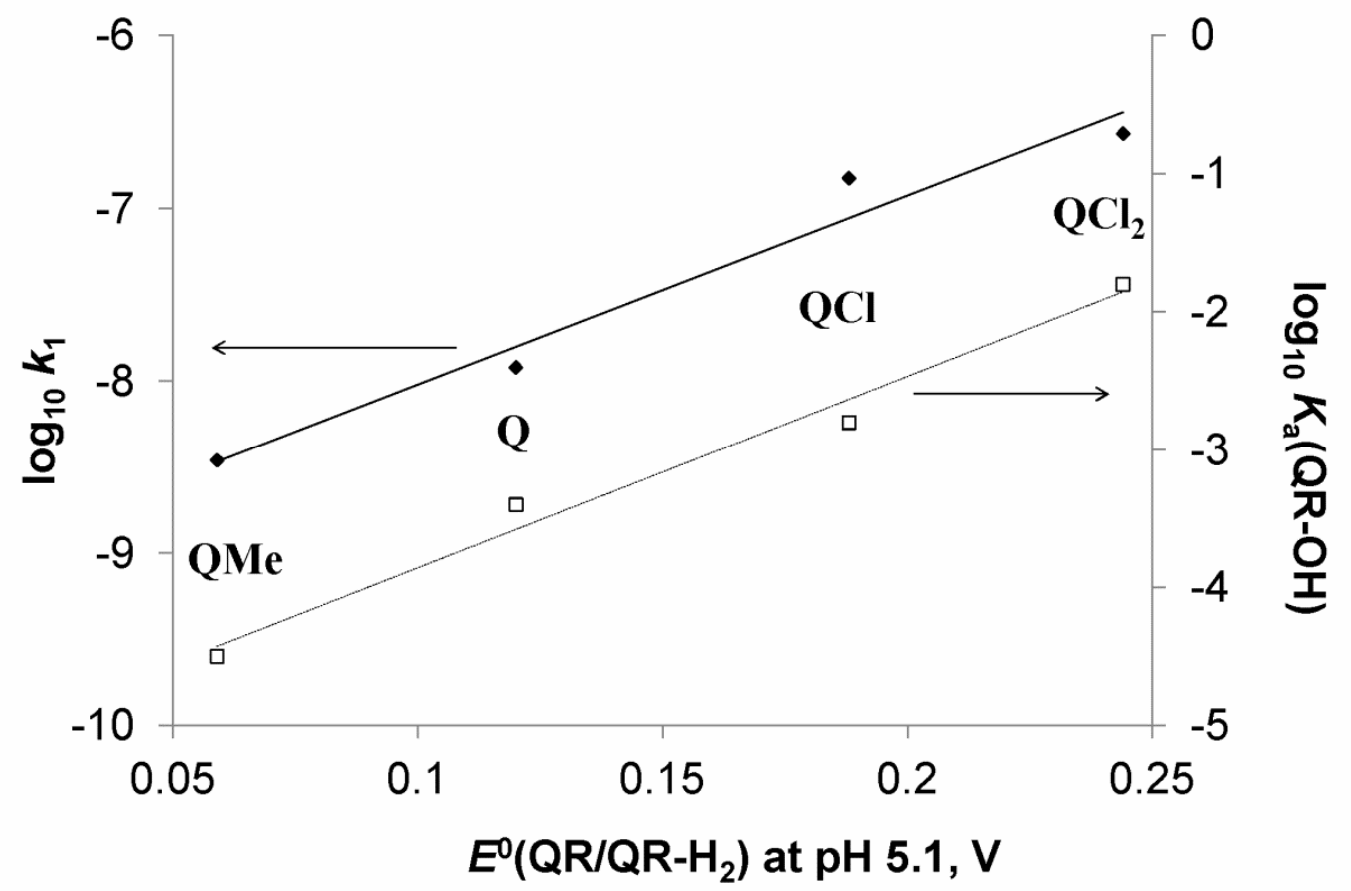

Figure 9: Linear correlation between $\log _{10} k_{1}$ values for the benzoquinone - hydrogen peroxide reactions (primary y axes, $\bullet$ ), $\log _{10} K_{\mathrm{a}}$ values of the hydroxyquinones (secondary y axes, $\square$ ) and formal redox potentials of the benzoquinone/hydroquinone systems ( $\mathrm{x}$ axes)

Redox potential values as a function of $\mathrm{pH}$ were also measured. High cathodic and anodic peak separations were obtained under $\mathrm{pH} 4$ for all derivatives. This can be explained by dimeric/polymeric quinone compound formation on the surface of the working electrode that blocks free flow of electrons. Therefore, the virtual number of electrons is less than 2 (the expected value for quinone reduction/oxidation). ${ }^{64,65}$ 


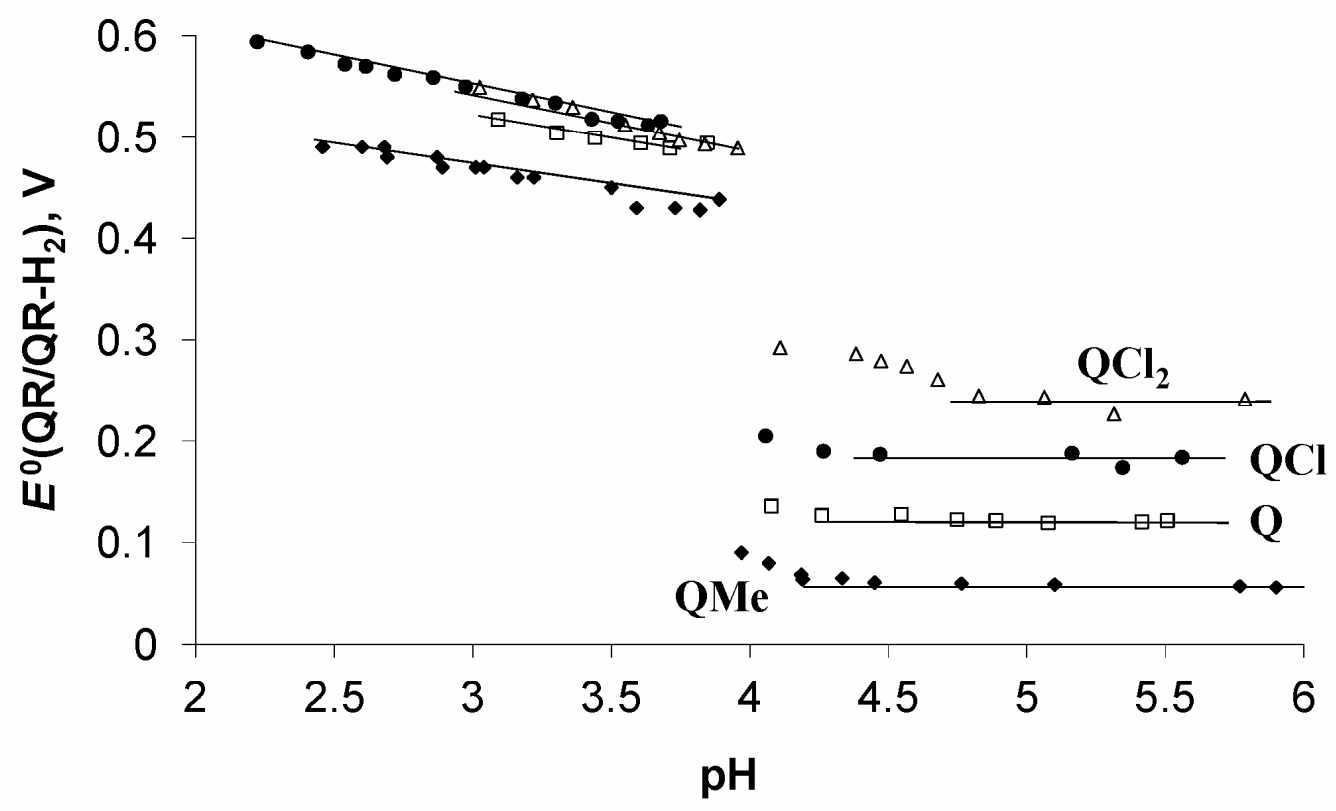

Figure 10: Pourbaix-diagram of different 1,4-benzoquinone derivatives: $\square=1$,4benzoquinone $(\mathrm{Q}), \bullet=2$-methyl-1,4-benzoquinone $(\mathrm{QMe}), \bullet=2$-chloro-1,4benzoquinone $(\mathrm{QCl})$ and $\Delta=2,6$-dichloro-1,4-benzoquinone $\left(\mathrm{QCl}_{2}\right)$

\subsection{Decomposition kinetics of the hydroxyquinone}

\subsubsection{Dependence of $k_{\Psi_{2}}$ and $k_{\Psi_{3}}$ on the hydrogen peroxide and hydrogen ion concentrations}

Fitting the kinetic curves yielded not only apparent rate constants for the hydroxyquinone formation, but also pseudo-first and -second order rate constants for the hydroxyquinone decomposition. These values are shown in Figure 11 for the 2-methyl derivative and in Table S5 of the Supplementary Information. Both $k_{\Psi_{2}}$ and $k_{\Psi_{3}}$ values show a linear dependence when fitted against $c\left(\mathrm{H}_{2} \mathrm{O}_{2}\right)$ under certain conditions. The $\mathrm{pH}$ dependence for the hydroxyquinone decomposition reaction is more complex and will not be discussed in this paper. 


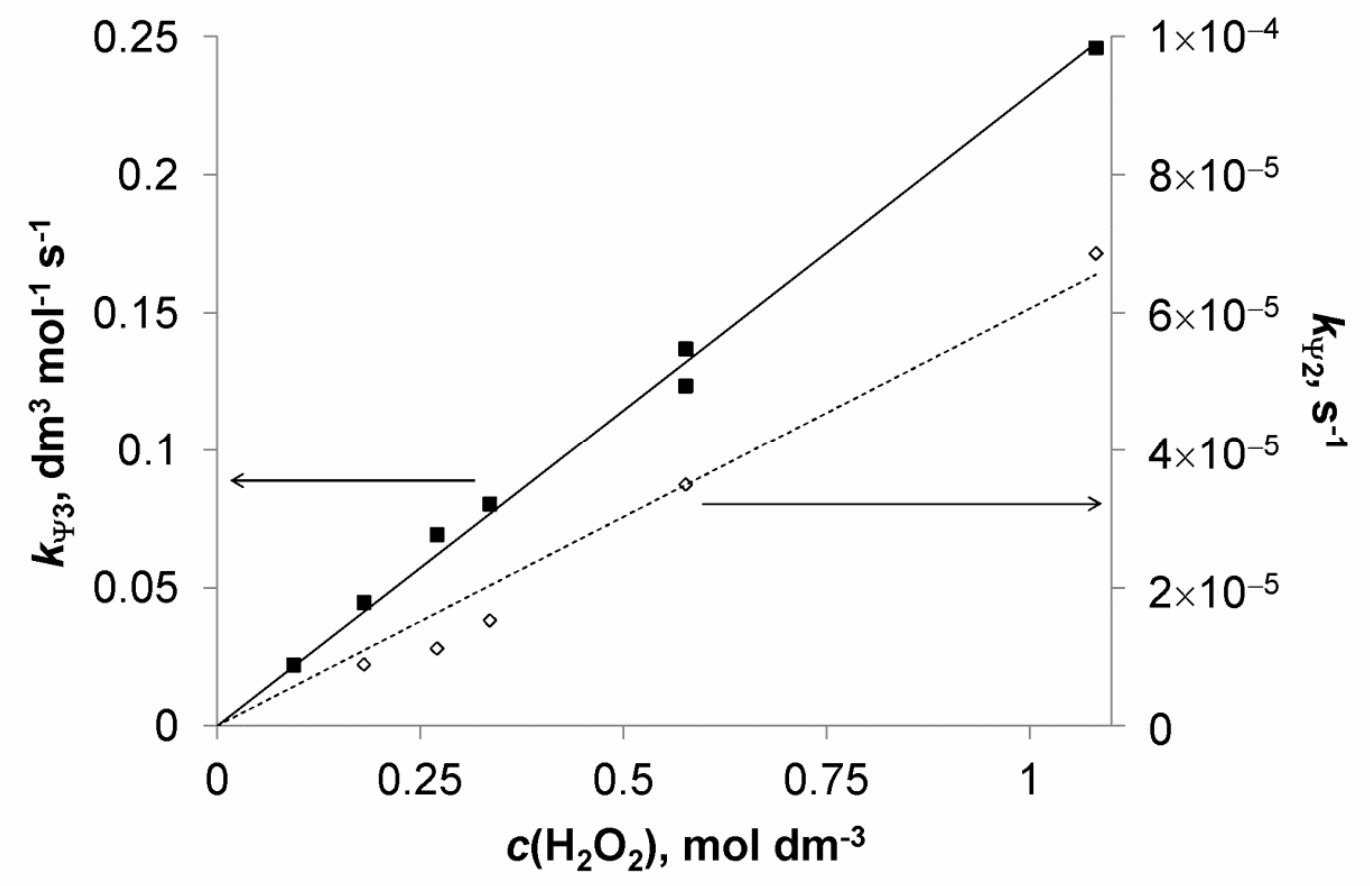

Figure 11: $\mathrm{H}_{2} \mathrm{O}_{2}$ concentration dependence of the $k_{\Psi_{2}}$ and $k_{\Psi_{3}}$ apparent rate constants in the 2-methyl-1,4-benzoquinone $(\mathrm{QMe})-\mathrm{H}_{2} \mathrm{O}_{2}$ system at $\mathrm{pH}$ 6.5-6.7 and $25.0{ }^{\circ} \mathrm{C}$

The main importance of the whole curve measurement and fitting for the determination of $k_{1}$ values is demonstrated by Figure 1 for 2-methyl-1,4-benzoquinone (and in the Supplementary Information by Figure S5 for 1,4-benzoquinone). In Figure 1, the concentration of 2-methyl-1,4-benzoquinone is the same in all samples. However, the maximum absorbance measured strongly depends on the concentration of the hydrogen peroxide $\left(A_{\max }=0.36\right.$ for $c\left(\mathrm{H}_{2} \mathrm{O}_{2}\right)=1.081 \mathrm{~mol} \mathrm{dm}^{-3}$ and $A_{\max }=0.21$ for $c\left(\mathrm{H}_{2} \mathrm{O}_{2}\right)=0.054 \mathrm{~mol}$ $\left.\mathrm{dm}^{-3}\right)$. This is even more characteristic when not only the $c\left(\mathrm{H}_{2} \mathrm{O}_{2}\right)$ but also the $\mathrm{pH}$ of the two solutions are different. In many cases, the increasing part of the curves can be fitted using a smaller molar absorption coefficient value than the real one and resulting in the calculation of 
a larger $k_{\Psi_{1}}$ than the real. To avoid this pitfall, a careful analysis of the calculated molar absorption coefficients was used, which involved an inspection of the effect of hydrogen peroxide concentration and the results were accepted only if there was no trend in the values. The other method to avoid this problem was a simultaneous fitting of all measured curves for a given derivative together with only one $\varepsilon\left(\mathrm{QR}-\mathrm{O}^{-}\right)$parameter. Additionally, full kinetic curves were measured in many cases and fitted to obtain even more reliable data for the first step.

Another reason for the $\mathrm{pH}$-dependent hydroxyquinone molar absorption coefficient values can be the deprotonation process of the hydroxyquinone derivative, which can be described by its $\mathrm{p} K_{\mathrm{a}}$ value. In the case of our measurements, however, this was never the case since all measurements were carried out at least $1 \mathrm{pH}$ unit above the $\mathrm{p} K_{\mathrm{a}}$ value of the appropriate 2-hydroxy-1,4-benzoquinone, so, the absorbing species was the deprotonated hydroxyquinone in all measurements and the determined molar absorption coefficient was the $\varepsilon\left(\mathrm{QR}-\mathrm{O}^{-}\right)$, not the $\varepsilon(\mathrm{QR}-\mathrm{OH})$.

\subsubsection{Attempts to identify the decomposition products}

To identify the decomposition products, both NMR and GC-MS measurements were performed. In the GC-MS spectra, we could identify the starting 2-methyl-1,4-benzoquinone before adding hydrogen peroxide to the sample. After adding hydrogen peroxide, dominating MS peaks with 44 and $32 \mathrm{~m} / \mathrm{z}$ values were found indicating a full oxidation of the sample to $\mathrm{CO}_{2}(44 \mathrm{~m} / \mathrm{z})$ as the final product and decomposition of the hydrogen peroxide excess to $\mathrm{O}_{2}$ (32 $\mathrm{m} / \mathrm{z}$ ) under GC-MS conditions. NMR measurements show that the hydroxyquinone decomposes (the intensity of the aromatic region decreases) but in the aliphatic region, there are new signals indicating the decomposition of the hydroxyquinone to smaller aliphatic fragments. 
It is also known from the spectrophotometric kinetic traces that the final products of the decomposition reactions have no absorbance at the wavelengths of the kinetic measurements (that is between 480 and $510 \mathrm{~nm}$ ). This is in good agreement with the findings of the other two techniques. 


\section{Conclusion}

The data presented here show that the reaction of hydrogen peroxide with 1,4-benzoquinone derivates is primarily determined by the electronic effects of the substituents. The formation of the intermediate hydroxylated quinone is first order with respect to both reagents, and inverse first order with respect to hydrogen ion. The process is accelerated by electron withdrawing substituents on the benzoquinone ring. The decomposition of the hydroxylquinone intermediate is mixed first and second order with respect to the limiting reagent, and depends on the concentrations of the oxidant and hydrogen ion in a more complex manner.

DFT calculations are in good agreement with the experimental data. The mechanism of the hydroxyquinone is a multi-step process where the rate determining step is the epoxide ring opening. The calculated energies are similar to the activation parameters. The mechanism is in agreement with the experimentally found rate equation. The 2-methyl-1,4-benzoquinone prefers the trans position for the formation of the 2-methyl-hydroxyquinone while the mechanism is the same as for the unsubstituted 1,4-benzoquinone. 


\section{Acknowledgements}

The research work performed by Éva Józsa for this manuscript was supported by the European Union and the State of Hungary, co-financed by the European Social Fund in the framework of TÁMOP 4.2.4. A/2-11-1-2012-0001 'National Excellence Program’.

Hungarian Science Funding Agency OTKA is also acknowledged for support under contract no. K77936.

The research was supported by the EU and co-financed by the European Social Fund under the projects ENVIKUT (TÁMOP-4.2.2.A-11/1/KONV-2012-0043) and TÁMOP 4.2.2/B10/1-2010-0024.

This work was partially supported by the European Union and the European Social Fund through project Supercomputer, the national virtual lab, grant no.: TÁMOP-4.2.2.C11/1/KONV-2012-0010.

The authors wish to thank Sarolta Timári, Lajos Nagy, Zoltán Nagy, Gábor Lente and Mónika Galajda for helpful discussions. 


\section{References}

1 M.Y. Okamura, M.L. Paddock, M.S. Graige and G. Feher, Biochim. Biophys. Acta, 2000, 1458, 148.

2 M. Kawamukai, J. Biosci. Bioeng., 2002, 94, 511.

3 T. Yagishita, S. Sawayama, K. Tsukahara and T. Ogi, J. Biosci. Bioeng., 1999, 88, 210.

4 S. Tsujimura, A. Wadano, K. Kano and T. Ikeda, Enzyme Microb. Technol., 2001, 225.

$5 \quad$ P.A. Leighton and G.S. Forbes, J. Am. Chem. Soc., 1929, 51, 3549.

6 G. Lente and J.H. Espenson, J. Photochem. Photobiol., A, 2004, 163, 249.

7 H.I. Joschek and S.I. Miller, J. Am. Chem. Soc., 1966, 88, 3273.

8 A. Pochon, P.P. Vaughan, D. Gan, P. Vath, N.V. Blough and D.E. Falvey, J. Phys. Chem., A, 2002, 106, 2889.

9 A.D. Broadbent and R.P. Newton, Can. J. Chem., 1972, 50, 381.

10 S. Spyroudis, Molecules, 2000, 5, 1291.

11 J.F.W. McOmie and J.M. Blatchly, The Thiele-Winter acetoxylation of quinones in Organic Reactions, Wiley, New York, 1972, vol. 19, pp. 199.

12 K.T. Finley, in The Chemistry of the Quinoid Compounds, ed. S. Patai and Z. Rappoport, Wiley-Interscience, New York, 1988, vol. 2, pp. 537.

13 D. Villemin, N. Bar and M. Hammadi, Tetrahedron Lett., 1997, 38, 4777.

14 W.P. Almeida and C.R.D. Correia, Tetrahedron Lett., 1994, 35, 1367.

15 M.V. Sargent and S. Wangchareontrakul, J. Chem. Soc., Perkin Trans., 1990, 1429.

16 H. Suginome, H. Kamekawa, H. Sakurai, A. Konishi, H. Senboku and K. Kobayashi, J. Chem. Soc., Perkin Trans., 1994, 471.

17 R. Huot and P. Brassard, Can. J. Chem., 1974, 52, 88.

18 E. Waldhör, B. Schwederski and W. Kaim, J. Chem. Soc., Perkin Trans., 1993, 2109.

19 G.C.A. Luijkx, F. van Rantwijk and H. van Bekkum, Carbohydr. Res., 1993, 242, 131. 
20 K. Kobayashi, Y. Kanno and H. Suginome, J. Chem. Soc., Perkin Trans., 1993, 1449.

21 S. Poigny, M. Guyot and M. Samadi, Tetrahedron, 1998, 54, 14791.

22 S. Poigny, M. Guyot and M. Samadi, J. Org. Chem., 1998, 63, 5890.

23 T. Yoon, S.J. Danishefski and S. de Cala, Angew. Chem., Int. Ed. Engl., 1994, 33, 853.

24 G. Lente and J.H. Espenson, New J. Chem., 2004, $28,847$.

25 J.M. Campos-Martin, G. Blanco-Brieva and J.L.G. Fierro, Angew. Chem., Int. Ed., 2006, 45, 6962.

26 C.E. Crouthamel, H.V. Meek, D.S. Martin and C.V. Banks, J. Am. Chem. Soc., 1949, 71, 3031.

27 K. Kustin and E. C. Lieberman, J. Phys. Chem., 1964, 68, 3869.

28 I. Pecht and Z. Lutz, J. Am. Chem. Soc., 1965, 87, 4068.

29 J. Evans, W. Levason and M.D. Spicer, J. Chem. Soc., Dalton Trans., 1990, 2307.

30 I. Kerezsi, G. Lente and I. Fábián, Dalton Trans., 2004, 342.

31 K.C. Kurien and P.A. Robins, J. Chem. Soc. B, 1970, 855.

32 M. Shirai, T. Awatsuji and M. Tanaka, Bulletin of the Chemical Society of Japan, 1975, 48, 1329.

33 A.I. Ononye, A.R. McIntosh and J.R. Bolton, J. Phys. Chem., 1986, 90, 6266.

34 A.I. Ononye and J.R. Bolton, J. Phys. Chem., 1986, 90, 6270.

35 A.E. Alegría, A. Ferrer and E. Sepúlveda, Photochem. Photobiol., 1997, 66, 436.

36 A.E. Alegría, A.Ferrer, G. Santiago and E. Sepúlveda, W. Flores, J. Photochem. Photobiol., A, 1999, 127, 57.

37 H. Görner and C. Sonntag, J. Phys. Chem. A, 2008, 112, 10257.

38 B. Tonomura, H. Nakatani, M. Ohnishi, J. Yamaguchi-Ito and K. Hiromi, Anal. Biochem., 1978, 84, 370.

39 Scientist 2.01, Micromath Software, Salt Lake City, UT, 1995. 
40 E. Farkas, P. Buglyó, É.A. Enyedy and M.A. Santos, Inorg. Chim. Acta, 2004, 357, 2451.

41 A.W. Bott, Current Separations, 1995, 14, 64.

42 http://spectroline.drupalgardens.com/content/fc-series

43 T. Lehóczki, É. Józsa and K. Ösz, J. Photochem. Photobiol., A, 2013, 251, 63.

44 M. Gombár, É. Józsa, M. Braun and K. Ösz, Photochem. Photobiol. Sci., 2012, 11, 1592.

45 A.D. Becke, J. Chem. Phys., 1993, 98, 5648.

46 C. Lee, W. Yang and R.G. Parr, Phys. Rev., 1988, B37, 785.

47 P.J. Stephens, F.J. Devlin, C.F. Chabalowski and M.J. Frisch, J. Phys. Chem., 1994, 98, 11623.

48 J. Tomasi, B. Mennucci and R. Cammi, Chem. Rev., 2005, 105, 2999.

49 G. Scalmani and M.J. Frisch, J. Chem. Phys., 2010, 11, 114110.

50 J. Tomasi, B. Mennucci and E. Cancès, J. Mol. Struct. (Theochem), 1999, 464, 211.

51 J.L. Pascual-Ahuir, E. Silla and I. Tuñón, J. Comp. Chem., 1994, 15, 1127.

52 C. Peng, P.Y. Ayala, H.B. Schlegel and M.J. Frisch, J. Comput. Chem., 1996, 17, 49.

53 C. Peng and H.B. Schlegel, Isr. J. Chem., 1994, 33, 449.

54 M. Head-Gordon, J.A. Pople and M.J. Frisch, Chem. Phys. Lett., 1988, 153, 503.

55 M. Head-Gordon and T. Head-Gordon, Chem. Phys. Lett., 1994, 220, 122.

56 S. Saebo and J. Almlof, Chem. Phys. Lett., 1989, 154, 83.

57 M.J. Frisch, M. Head-Gordon and J.A. Pople, Chem. Phys. Lett., 1990, 166, 275.

58 M.J. Frisch, M. Head-Gordon and J.A. Pople, Chem. Phys. Lett., 1990, 166, 281.

59 M.J. Frisch, G.W. Trucks, H.B. Schlegel, G.E. Scuseria, M.A. Robb, J.R. Cheeseman, G. Scalmani, V. Barone, B. Mennucci, G.A. Petersson, H. Nakatsuji, M. Caricato, X. Li, H.P. Hratchian, A.F. Izmaylov, J. Bloino, G. Zheng, J.L. Sonnenberg, M. Hada, M. 
Ehara, K. Toyota, R. Fukuda, J. Hasegawa, M. Ishida, T. Nakajima, Y. Honda, O. Kitao, H. Nakai, T. Vreven, J.A. Montgomery, J.E. Peralta, F. Ogliaro, M. Bearpark, J. J. Heyd, E. Brothers, K.N. Kudin, V.N. Staroverov, R. Kobayashi, J. Normand, K. Raghavachari, A. Rendell, J.C. Burant, S.S. Iyengar, J. Tomasi, M. Cossi, N. Rega, N.J. Millam, M. Klene, J.E. Knox, J.B. Cross, V. Bakken, C. Adamo, J. Jaramillo, R. Gomperts, R.E. Stratmann, O. Yazyev, A.J. Austin, R. Cammi, C. Pomelli, J.W. Ochterski, R.L. Martin, K. Morokuma, V.G. Zakrzewski; G.A. Voth, P. Salvador, J.J. Dannenberg, S. Dapprich, A.D. Daniels, Ö. Farkas, J.B. Foresman, J.V. Ortiz, J. Cioslowski and D.J. Fox, Gaussian 09, Gaussian, Inc.: Wallingford CT, 2009.

60 M.G. Evans and N. Uri., Trans. Faraday Soc., 1949, 45, 224.

61 G. Lente, I. Fábián and A.J. Poe, New J. Chem., 2005, 29, 759.

62 T. Hosoya and T. Rosenau, J. Org. Chem., 2013, 78, 3176.

63 P. Li, W. Wang, S. Bi and H. Sun, Struct. Chem., 2013, 24, 1253.

64 R.D. Rieke, T. Saji and N. Kujundzic, J. Electroanal. Chem., 1979, 102, 397.

65 S.I. Bailey and I.N. Ritchie, Electrochim. Acta, 1985, 30, 3. 